\title{
ASME Code Considerations for the Compact Heat Exchanger
}

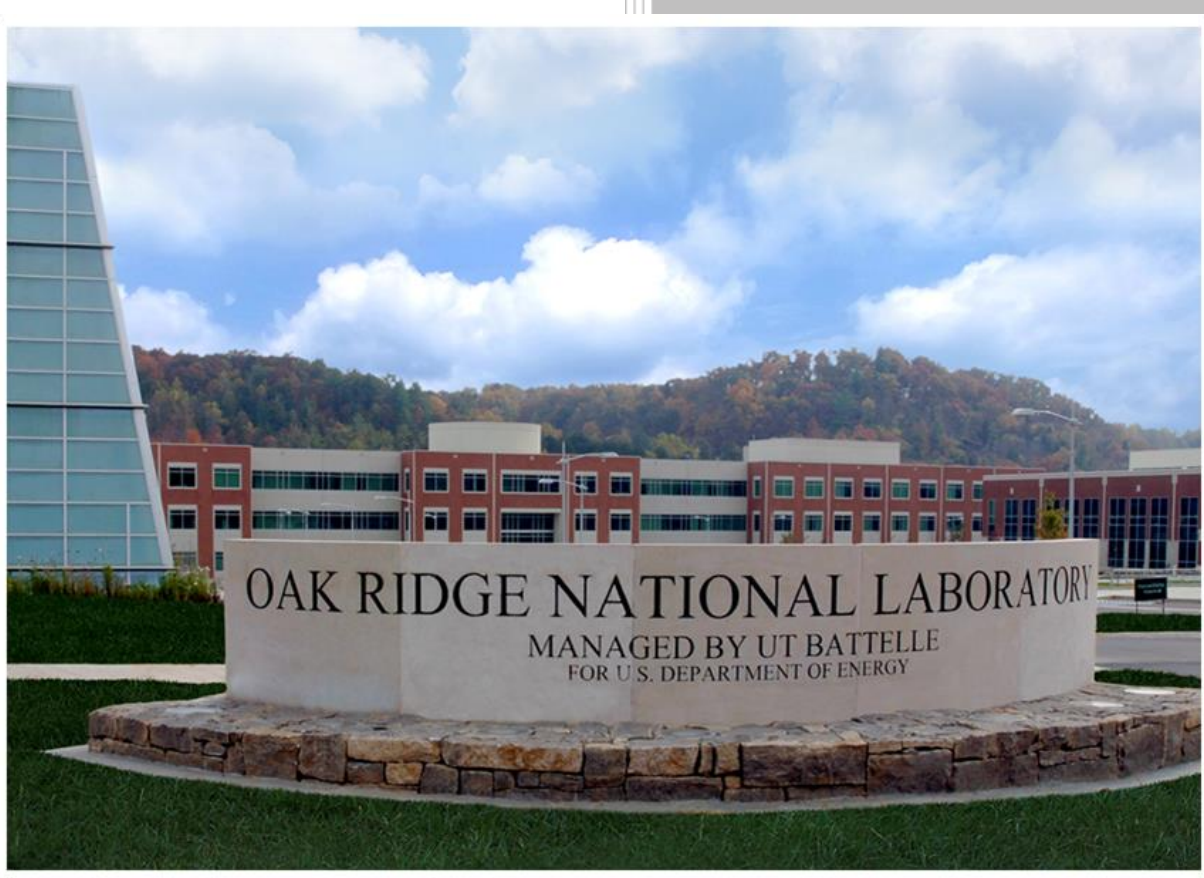

Approved for public release;

distribution is unlimited.
J. Nestell

MPR Associates, Inc.

T.-L. Sham

Oak Ridge National Laboratory

August 31, 2015 


\section{DOCUMENT AVAILABILITY}

Reports produced after January 1, 1996, are generally available free via US Department of Energy (DOE) SciTech Connect.

Website http://www.osti.gov/scitech/

Reports produced before January 1,1996, may be purchased by members of the public from the following source:

National Technical Information Service

5285 Port Royal Road

Springfield, VA 22161

Telephone 703-605-6000 (1-800-553-6847)

TDD 703-487-4639

Fax 703-605-6900

E-mail info@ntis.gov

Website http://www.ntis.gov/help/ordermethods.aspx

Reports are available to DOE employees, DOE contractors, Energy Technology Data Exchange representatives, and International Nuclear Information System representatives from the following source:

Office of Scientific and Technical Information

PO Box 62

Oak Ridge, TN 37831

Telephone 865-576-8401

Fax 865-576-5728

E-mail reports@osti.gov

Website http://www.osti.gov/contact.html

This report was prepared as an account of work sponsored by an agency of the United States Government. Neither the United States Government nor any agency thereof, nor any of their employees, makes any warranty, express or implied, or assumes any legal liability or responsibility for the accuracy, completeness, or usefulness of any information, apparatus, product, or process disclosed, or represents that its use would not infringe privately owned rights. Reference herein to any specific commercial product, process, or service by trade name, trademark, manufacturer, or otherwise, does not necessarily constitute or imply its endorsement, recommendation, or favoring by the United States Government or any agency thereof. The views and opinions of authors expressed herein do not necessarily state or reflect those of the United States Government or any agency thereof. 
Advanced Reactor Technologies Program

\title{
ASME CODE CONSIDERATIONS FOR THE COMPACT HEAT EXCHANGER
}

\author{
J. Nestell \\ MPR Associates, Inc. \\ T.-L. Sham \\ Oak Ridge National Laboratory
}

Date Published: August 31, 2015

Prepared under the direction of the

U.S. Department of Energy

Office of Nuclear Energy

Prepared by

OAK RIDGE NATIONAL LABORATORY

Oak Ridge, TN 37831-6283

managed by

UT-BATTELLE, LLC

for the

US DEPARTMENT OF ENERGY

under contract DE-AC05-00OR22725 
Page Intentionally Blank 


\section{ACKNOWLEDGMENTS}

This research was sponsored by the U.S. Department of Energy. Programmatic direction was provided by the Advanced Reactor Technologies (ART) Program of the Office of Nuclear Energy (NE). We gratefully acknowledge the support provided by Carl Sink of DOE-NE, ART Program Manager; William Corwin of DOE-NE, ART Materials Technology Lead; and David Petti of Idaho National Laboratory, ART CoNational Technical Director.

The authors are grateful to Robert Jetter for helpful discussions. The time spent by Jy-An Wang of Oak Ridge National Laboratory in reviewing this report is also greatly appreciated. 
Page Intentionally Blank 


\begin{abstract}
The mission of the U.S. Department of Energy (DOE), Office of Nuclear Energy is to advance nuclear power in order to meet the nation's energy, environmental, and energy security needs. Advanced high temperature reactor systems such as sodium fast reactors and high and very high temperature gas-cooled reactors are being considered for the next generation of nuclear reactor plant designs.

The coolants for these high temperature reactor systems include liquid sodium and helium gas. Supercritical carbon dioxide $\left(\mathrm{sCO}_{2}\right)$, a fluid at a temperature and pressure above the supercritical point of $\mathrm{CO}_{2}$, is currently being investigated by DOE as a working fluid for a nuclear or fossil-heated recompression closed Brayton cycle energy conversion system that operates at $550^{\circ} \mathrm{C}\left(1022^{\circ} \mathrm{F}\right)$ at 200 bar (2900 psi). Higher operating temperatures are envisioned in future developments. All of these design concepts require a highly effective heat exchanger that transfers heat from the nuclear or chemical reactor to the chemical process fluid or to the power cycle.

In the nuclear designs described above, heat is transferred from the primary to the secondary loop via an intermediate heat exchanger (IHX) and then from the intermediate loop to either a working process or a power cycle via a secondary heat exchanger (SHX). The IHX is a component in the primary coolant loop which will be classified as "safety related." The intermediate loop will likely be classified as "not safety related but important to safety." These safety classifications have a direct bearing on heat exchanger design approaches for the IHX and SHX.

The very high temperatures being considered for the VHTR will require the use of very high temperature alloys for the IHX and SHX. Material cost considerations alone will dictate that the IHX and SHX be highly effective; that is, provide high heat transfer area in a small volume. This feature must be accompanied by low pressure drop and mechanical reliability and robustness. Classic shell and tube designs will be large and costly, and may only be appropriate in steam generator service in the SHX where boiling inside the tubes occurs. For other energy conversion systems, all of these features can be met in a compact heat exchanger design.

This report will examine some of the ASME Code issues that will need to be addressed to allow use of a Code-qualified compact heat exchanger in IHX or SHX nuclear service. Most effort will focus on the IHX, since the safety-related (Class A) design rules are more extensive than those for important-to-safety (Class B) or commercial rules that are relevant to the SHX.
\end{abstract}


Page Intentionally Blank 


\section{CONTENTS}

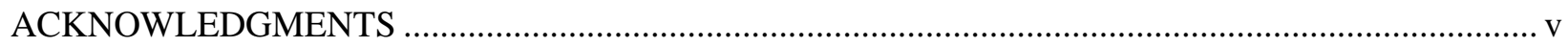

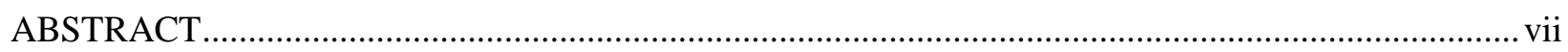

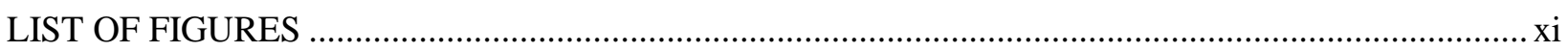

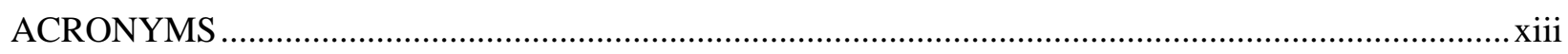

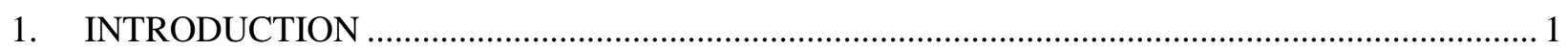

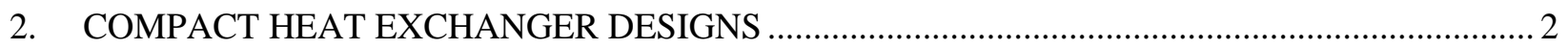

2.1 BRAZED PLATE-FIN HEAT EXCHANGER .......................................................... 2

2.2 FUSION WELDED FORMED PLATE DESIGNS …................................................. 4

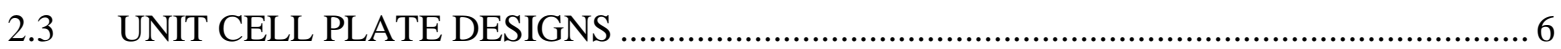

2.4 DIFFUSION BONDED (DIFFUSION WELDED) DESIGNS ........................................ 9

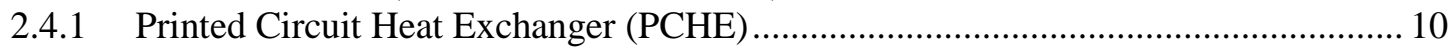

2.4.2 Formed Plate Diffusion Bonded Heat Exchanger .................................................. 14

2.4.3 Diffusion Bonded, Unit Cell Plate Heat Exchanger ................................................ 15

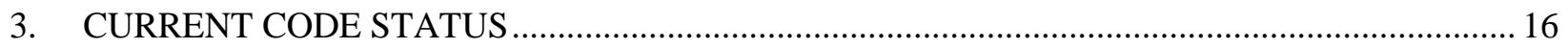

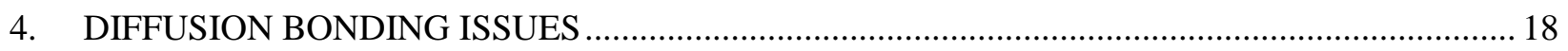

5. MECHANICAL DESIGN APPROACHES FOR MICROCHANNEL HEAT

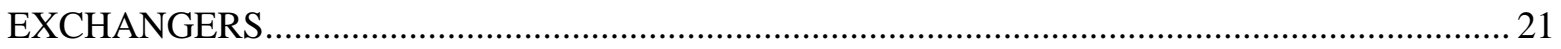

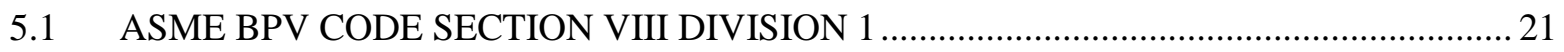

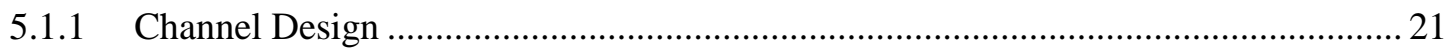

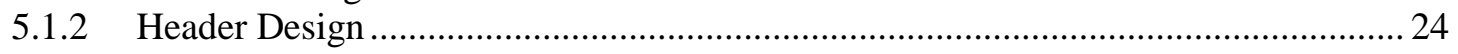

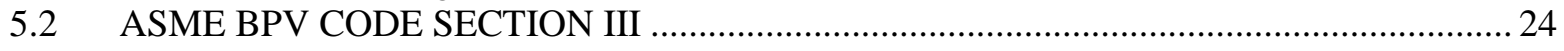

5.2.1 Section III, Division 5, Subsection HB, Subpart B Design for Class A Service ........ 24

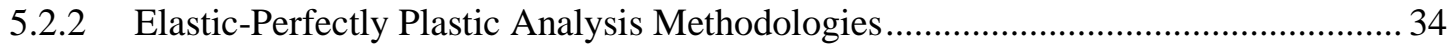

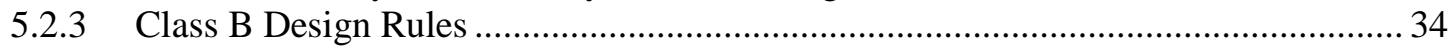

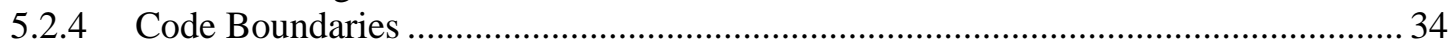

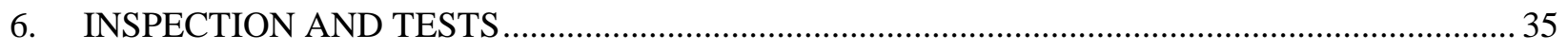

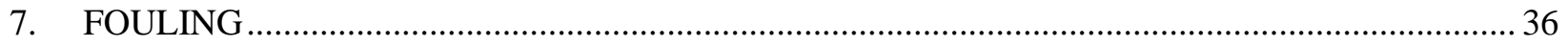

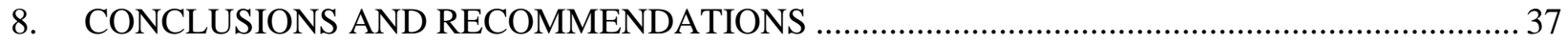

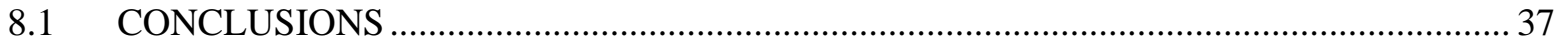

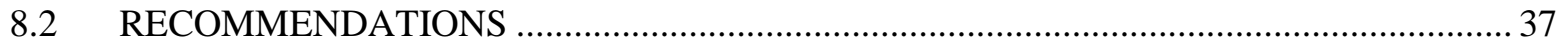

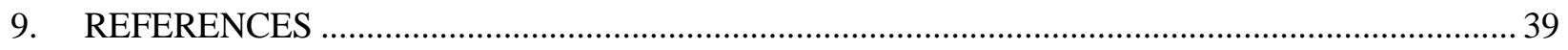


Page Intentionally Blank 


\section{LIST OF FIGURES}

Fig. 1. Components of brazed plate fin-heat exchanger.................................................................. 2

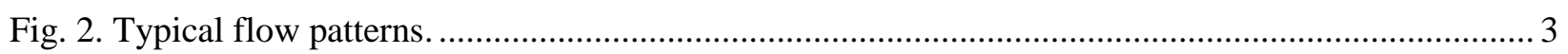

Fig. 3. Braze fillet at a plate-to-fin interface. After Ref 17. Reprinted with permission from Brayton

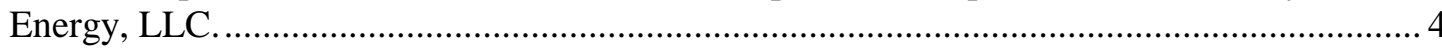

Fig. 4. Formed plate heat exchanger with welded edges, Tranter Heat Exchangers. Reprinted with

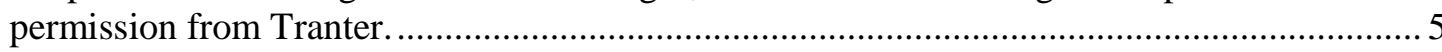

Fig. 5. Plate heat exchanger flow paths, Tranter Heat Exchangers. Reprinted with permission from

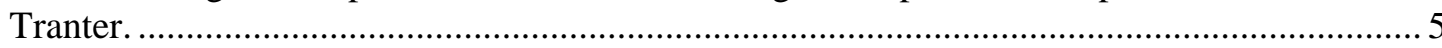

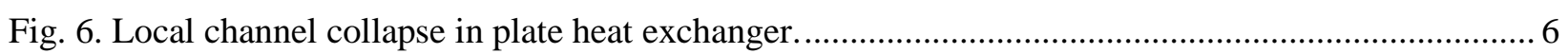

Fig. 7. Unit cell heat exchanger component parts. Reprinted with permission from Brayton Energy, LLC.

Fig. 8. Unit cell heat exchanger assembly. Reprinted with permission from Brayton Energy, LLC............ 7

Fig. 9. Unit cell heat exchanger crossflow. Reprinted with permission from Brayton Energy, LLC. .......... 8

Fig. 10. Unit cell layer containing high pressure cell and low pressure external fins................................ 8

Fig. 11. Unit cell HX in counterflow operation. After Ref 18. Reprinted with permission, ....................... 9

Fig. 12. Diffusion bond recrystallization process. After Ref 1. Reprinted with permission....................... 10

Fig. 13. Chemical etch patterns for cross/counterflow PCHE. ............................................................... 11

Fig. 14. (a) Plate stacking for bonding (cross/counterflow) (b) Bonded printed circuit core (cross flow subsection). After Ref 6. Reprinted with permission................................................... 11

Fig. 15. Bonded section showing complete recrystallization. After Ref 5. Repeated with permission. ..... 11

Fig. 16. Cross flow etching pattern. After Ref 7, Copyright 2010 by the American Nuclear Society, La Grange Park, Illinois. Reprinted with permission. ............................................................. 12

Fig. 17. Cross/counter flow channel etch pattern. After Ref 7, Copyright 2010 by the American Nuclear Society, La Grange Park, Illinois. Reprinted with permission................................. 12

Fig. 18. Serpentine counter flow etch pattern. After Ref 7, Copyright 2010 by the American Nuclear Society, La Grange Park, Illinois. Reprinted with permission.

Fig. 19. (a) Plate stack showing buildup of internal headers. After Ref 7, Copyright 2010 by the American Nuclear Society, La Grange Park, Illinois. Reprinted with permission. (b) Finished multi-block heat exchanger containing external "D" headers and internal ported headers. After Ref 8, Copyright 2009 by the American Nuclear Society, La Grange Park, Illinois. Reprinted with permission.

Fig. 20. Multi-block core during fabrication. After Ref 7, Copyright 2010 by the American Nuclear Society, La Grange Park, Illinois. Reprinted with permission.

Fig. 21. (a) Section VIII U-Stamp PCHE with cross/counter flow configuration shown in Fig. 14a. After Ref 5. Reprinted with permission. (b) Configuration of flows and headers for cross/counter flow configuration in Fig. 14a.

Fig. 22. Finished multiblock heat exchanger showing headers. After Ref 7, Copyright 2010 by the American Nuclear Society, La Grange Park, Illinois. Reprinted with permission. 
Fig. 23. Close-up views of diffusion-bonded formed plate (left) and printed circuit (right) channels. Arrows indicate loads perpendicular and parallel to the bond joint. After Ref 7, Copyright 2010 by the American Nuclear Society, La Grange Park, Illinois. Reprinted with permission.

Fig. 24. Composite heat exchanger core with alternating layers of etched and formed plate channels. After Ref 7, Copyright 2010 by the American Nuclear Society, La Grange Park, Illinois. Reprinted with permission.

Fig. 25. Diffusion bond showing residual particles (probably oxides). After Ref 11. Reprinted with permission from Elsevier.

Fig. 26. Properly bonded core (crossflow section). After Ref 9, Copyright 2008 by the American Nuclear Society, La Grange Park, Illinois. Reprinted with permission.

Fig. 27. Schematic of etched channel design (above) and simplified rectilinear model (below). After

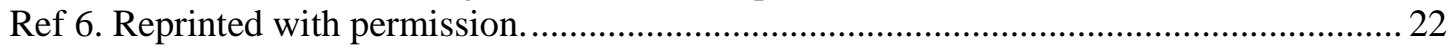

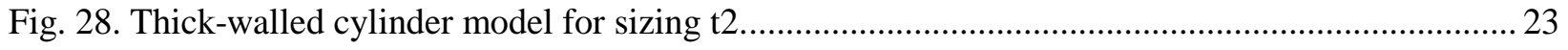

Fig. 29. Major components of the compact heat exchanger. 25

Fig. 30. (a) Finite element model of etched channels in a hydrogen cooler with pressure on one side only. (b) Pressure stresses in channel. Peaking in " $\mathrm{D}$ " corner is observed, but corner radius is expected to be much smaller (higher peak stresses) in actual microchannel designs. After Ref 5. Reprinted with permission.

Fig. 31. Thermal stress field near core/sidewall interface.

Fig. 32. Complex thermal/mechanical interactions at header locations during core cooling transients.

Fig. 33. (a) through (i) show the design of compact heat exchanger modules inside a Section III vessel. After Ref 13. 30

Fig. 34. Model suggested here for calculating areal density of channels.

Fig. 35. Principal axes for identifying orthotropic properties. 32

Fig. 36. Channel array finite element model for calculating localized stresses in channel walls. After Ref 16. 


\section{ACRONYMS}

$\begin{array}{ll}\text { ASME } & \text { American Society of Mechanical Engineers } \\ \text { BPV } & \text { boiler and pressure vessel } \\ \text { DFW } & \text { diffusion welding } \\ \text { DOE } & \text { Department of Energy } \\ \text { FPHE } & \text { formed plate heat exchanger } \\ \text { HTGR } & \text { high temperature gas-cooled reactor } \\ \text { HX } & \text { heat exchanger } \\ \text { IHX } & \text { intermediate heat exchanger } \\ \text { INL } & \text { Idaho National Laboratory } \\ \text { MIT } & \text { Massachusetts Institute of Technology } \\ \text { NDE } & \text { non destructive examination } \\ \text { NGNP } & \text { next generation nuclear plant } \\ \text { PCHE } & \text { printed circuit heat exchanger } \\ \text { PFHE } & \text { plate-fin heat exchanger } \\ \text { R\&D } & \text { research and development } \\ \text { sCO } & \text { supercritical carbon dioxide } \\ \text { SFR } & \text { sodium fast reactor } \\ \text { SHX } & \text { secondary heat exchanger } \\ \text { UCHE } & \text { unit cell heat exchanger } \\ \text { VHTR } & \text { very high temperature reactor } \\ \text { VPE } & \text { Vacuum Process Engineering } \\ & \end{array}$


Page Intentionally Blank 


\section{INTRODUCTION}

The mission of the U.S. Department of Energy (DOE), Office of Nuclear Energy is to advance nuclear power in order to meet the nation's energy, environmental, and energy security needs. Advanced high temperature reactor systems are being considered for the next generation of nuclear reactor plant designs. Sodium Fast Reactor (SFR), with an outlet temperature of $550^{\circ} \mathrm{C}\left(1022^{\circ} \mathrm{F}\right)$, is a leading candidate for several possible missions, including recycling of used fuel for closing the fuel cycle and for power generation. Other reactor systems considered are high and very high temperature gas-cooled reactors (HTGRs and VHTRs), with core outlet temperatures in the range of 750 to $950^{\circ} \mathrm{C}$ (1382 to $1742^{\circ} \mathrm{F}$ ), to support high temperature chemical processes such as hydrogen production and for power generation.

The coolants for these high temperature reactor systems include liquid sodium and helium gas. Supercritical carbon dioxide $\left(\mathrm{sCO}_{2}\right)$, a fluid at a temperature and pressure above the supercritical point of $\mathrm{CO}_{2}$, is currently being investigated by DOE as a working fluid for a nuclear or fossil-heated recompression closed Brayton cycle energy conversion system that operates at $550^{\circ} \mathrm{C}\left(1022^{\circ} \mathrm{F}\right)$ at 200 bar (2900 psi). Higher operating temperatures are envisioned in future developments. All of these design concepts require a highly effective heat exchanger that transfers heat from the nuclear or chemical reactor to the chemical process fluid or to the power cycle.

The nuclear designs described above most often contain a primary coolant loop that is heated by the reactor core and an intermediate loop containing a similar coolant operating at a similar pressure. Heat is transferred from the primary to the secondary loop via an intermediate heat exchanger (IHX). Thus, the IHX can be a liquid-to-liquid (e.g., sodium-to-sodium) or gas-to-gas (e.g., helium-to-helium) design. Transfer of heat from the intermediate loop to the working process (e.g., to the sulfur-iodine hydrogen generation process) or to the power cycle (e.g., sodium-to- $\mathrm{sCO}_{2}$ for a Brayton cycle) is accomplished by a secondary heat exchanger (SHX) that can be a gas-to-gas or liquid-to-fluid design. The IHX is a component in the primary coolant loop which will be classified as "safety related." The intermediate loop will likely be classified as "not safety related but important to safety." These safety classifications have a direct bearing on heat exchanger design approaches for the IHX and SHX.

The very high temperatures being considered for the VHTR will require the use of very high temperature alloys for the IHX and SHX. Material cost considerations alone will dictate that the IHX and SHX be highly effective; that is, provide high heat transfer area in a small volume. This feature must be accompanied by low pressure drop and mechanical reliability and robustness. All of these features can be met in a compact heat exchanger design.

Classic shell and tube designs will be large and costly, and may only be appropriate in steam generator service in the SHX where boiling inside the tubes occurs. Potential steam quality issues associated with boiling and slug flow in the small flow channels in a compact heat exchanger, along with likely corrosion product fouling problems in those channels, may eliminate the compact heat exchanger from consideration for steam generator service.

This report will examine some of the ASME Code issues that will need to be addressed to allow use of a Code-qualified compact heat exchanger in IHX or SHX nuclear service. Most effort will focus on the IHX, since the safety-related (Class A) design rules are more extensive than those for important-to-safety (Class B) or commercial rules that are relevant to the SHX. 


\section{COMPACT HEAT EXCHANGER DESIGNS}

DOE is currently considering several compact heat exchanger designs for the SHX of high temperature reactor systems. They include (Reference 1):

- $\quad$ Brazed plate-fin heat exchanger (PFHE)

- $\quad$ Fusion bonded formed plate heat exchanger (FPHE)

- $\quad$ Fusion bonded unit cell heat exchanger (UCHE)

- $\quad$ Fusion bonded printed circuit heat exchanger (PCHE)

\subsection{BRAZED PLATE-FIN HEAT EXCHANGER}

The traditional brazed plate-fin heat exchanger is built up from partition plates, formed fins, and side bar material, as shown in Fig. 1.

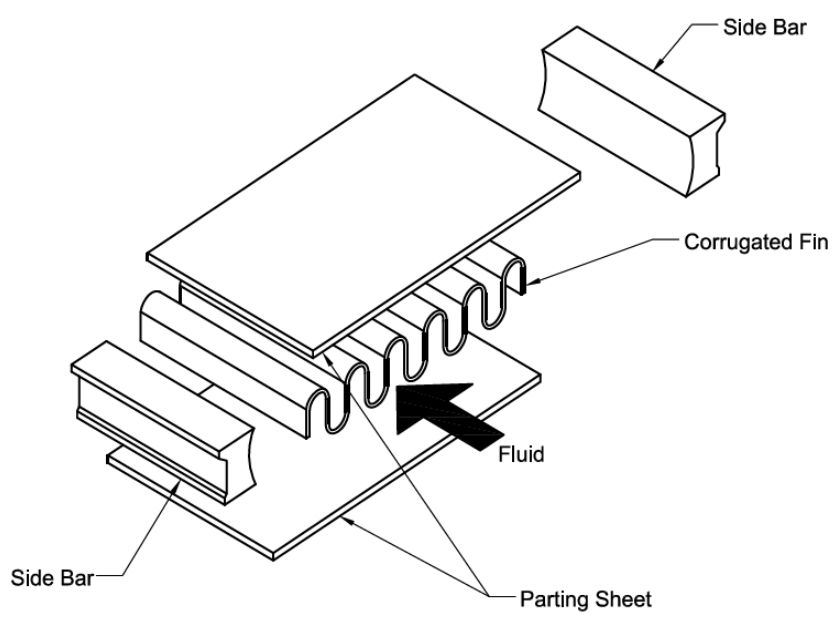

Fig. 1. Components of brazed plate fin-heat exchanger.

These layers are then built up to accommodate various flow patterns like counter flow, cross flow, etc., depending on thermal hydraulic design requirements. This is shown in Fig. 2. 


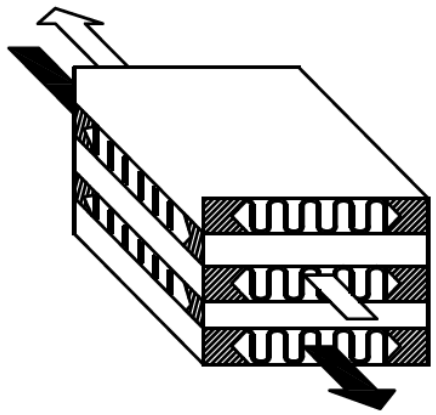

Countercurrent Flow

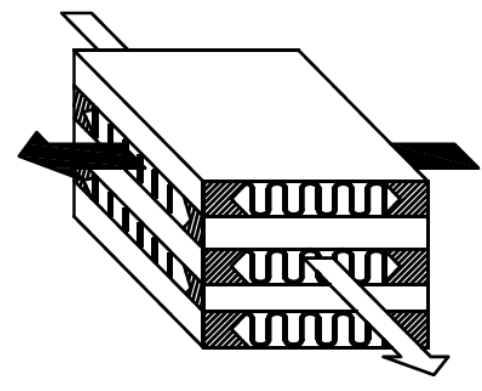

Cross Flow

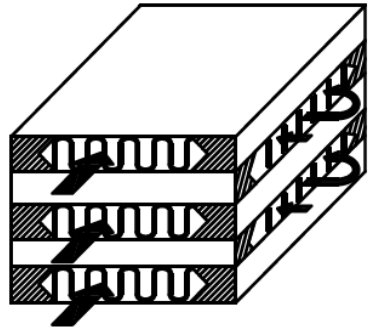

Cross-Countercurrent

Fig. 2. Typical flow patterns.

The heat exchanger is fabricated from a stack of alternating fluid A and fluid B layers which are then brazed together.

The plate-fin heat exchanger geometry has several nice features, as follows:

- It is very efficient from both a materials and thermal standpoint.

- It can handle moderately high pressures.

- $\quad$ Depending on the base metal and braze alloy, it can handle high temperatures.

- It can be made with relatively large channels to provide a low pressure drop in viscous fluids like liquid sodium.

On the other hand, the brazed plate-fin heat exchanger has limitations or vulnerabilities that would make it unsuitable for nuclear safety class service, as follows:

- $\quad$ The creep, fatigue and toughness of the braze joint is dependent on the braze alloy properties and brazing process control, not just the base metal properties. The braze alloy properties will likely be limiting for very high temperature service.

- $\quad$ Braze quality will depend on brazing process controls and surface preparation (cleaning). There is poor inspectability of brazes within the core.

- Joint strength and ductility also depend strongly on process controls for fin-to-partition-plate fit up, which can vary due to fin height and flatness variations. Controlling these requires tight control on fin rolling and forming processes.

- Depending on strength, ductility and strain hardening properties, some high temperature alloys like the nickel base super alloys may not be suitable for the fin forming operation.

- $\quad$ The melting temperature suppressant element in the braze alloy (typically, $\mathrm{P}$ or $\mathrm{B}$ in the nickel brazes) can produce brittle second phases in the braze itself (e.g. NiP) or in the base metal by diffusion (MoP, $\mathrm{MoP}_{3}$, or CrB in Alloy 617, for example), Reference 2. 
- $\quad$ The as-brazed heat exchanger structure contains very high residual stresses that can cause fin-to-partition plate cracking, Reference 3 . These cracks can easily go undetected and could be the initiators for premature fatigue or creep failures. The presence of as-brazed residual stresses requires that a post-braze stress relief be performed.

- The core structure is very rigid and subject to high thermal stresses if temperature gradients or transients are severe. Thermal stresses are likely to be limiting for large solid core designs.

- $\quad$ The peak operating stresses in the fin-to-plate joint depend on the braze fillet radius, which can be quite variable since it depends on fit up, volume of braze alloy, fin flatness, etc. See Fig. 3. It would be difficult to perform an analytic fatigue or creep evaluation of the joint because of the potential geometric variability and the resulting variability in peak stresses.

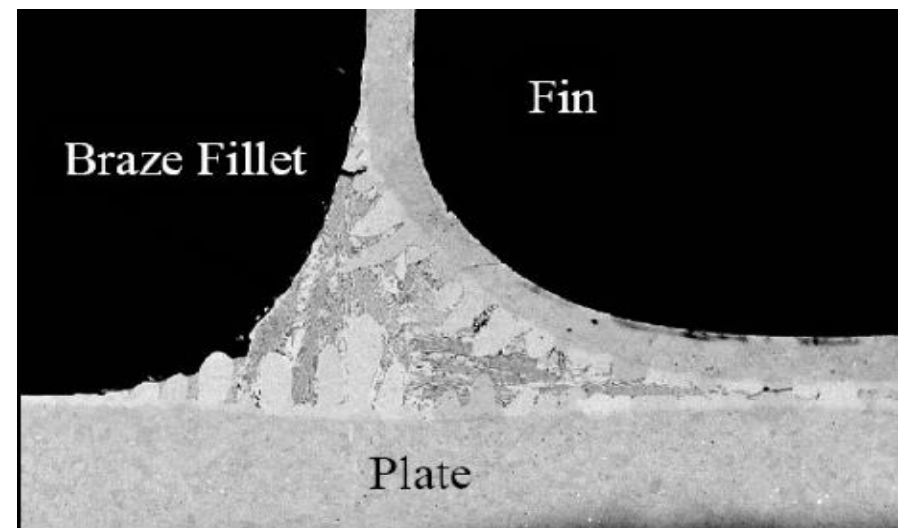

Fig. 3. Braze fillet at a plate-to-fin interface. After Ref 17. Reprinted with permission from Brayton Energy, LLC.

The process control uncertainties combined with the inability to inspect the majority of braze joints in a brazed plate-fin heat exchanger design probably make this design unsuitable for safety grade nuclear service. These are the unknown creep properties of the braze alloy at very high temperatures, the potential for base metal embrittlement at the joint interface, the indeterminate geometry of individual braze fillets, and potentially large thermal stresses in the rigid core during thermal transients or flow maldistributions conditions.

\subsection{FUSION WELDED FORMED PLATE DESIGNS}

There are a number of fusion welded compact heat exchanger designs that avoid braze quality and thermal stress problems described above. These are relatively low pressure formed plate designs where the "fins" are "herringbone" corrugations in the partition plates themselves. These designs incorporate the inlet and outlet headers in the plate stock itself. Some plate designs are shown in Fig. 4, and the flow and header arrangements are shown in Fig. 5. 

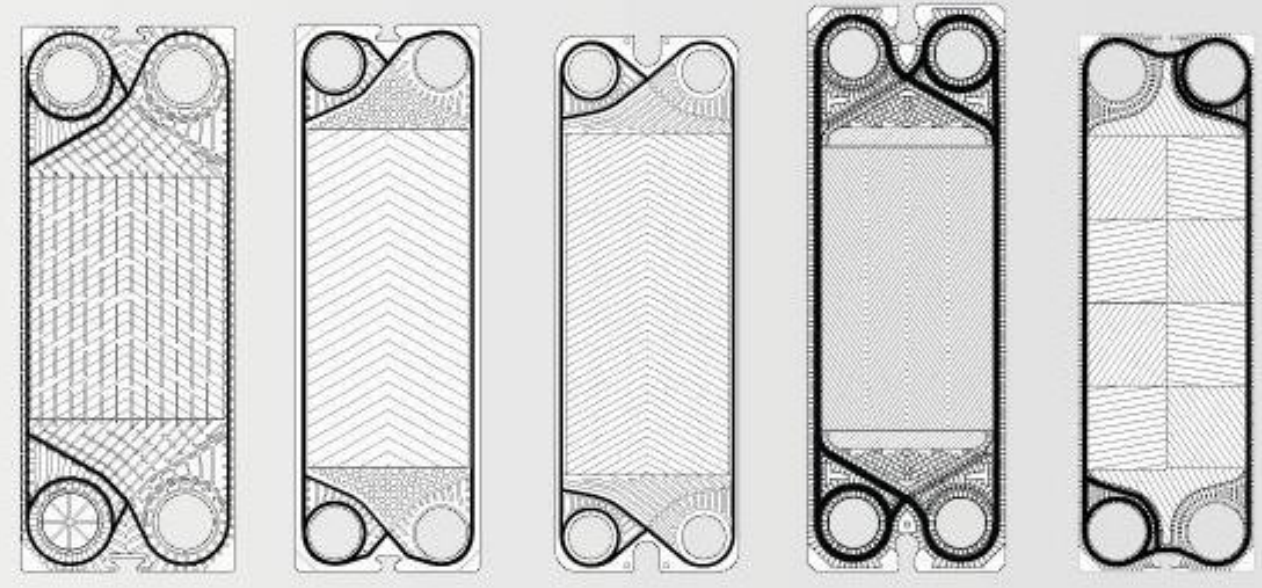

Fig. 4. Formed plate heat exchanger with welded edges, Tranter Heat Exchangers. Reprinted with permission from Tranter.

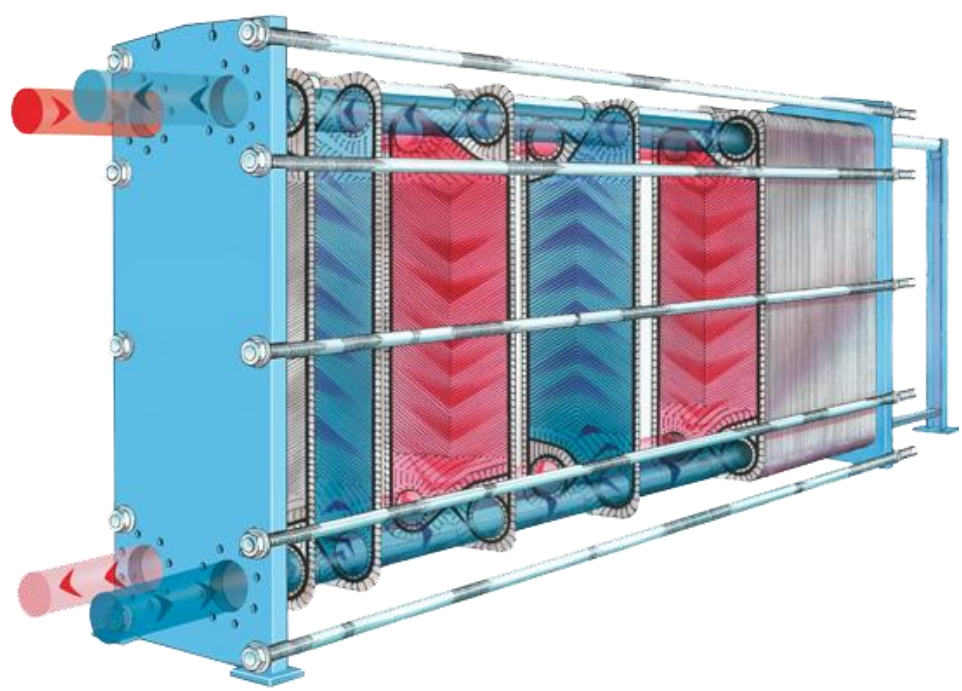

Fig. 5. Plate heat exchanger flow paths, Tranter Heat Exchangers. Reprinted with permission from Tranter.

The most limiting feature of the welded plate design is its inability to support high delta-P fluid conditions. The welding is limited to the plate edge and manifolds, leaving the middle of each plate unsupported for pressure loads. Pressure loads are usually resisted by a strong back or frame supporting the entire core, but some internal support can be obtained by local spot or plug welds between the partition plates in the center area in "quilted" or "dimpled" plate designs. But even if the stack is supported by a strong back or cage, under high delta-P fluid conditions, individual herringbone convolutions are subject to pressure loading which could lead to local herringbone collapse by creep deformation at high temperatures, ultimately choking off of the low pressure layers in the stack. See Fig. 6, below. 

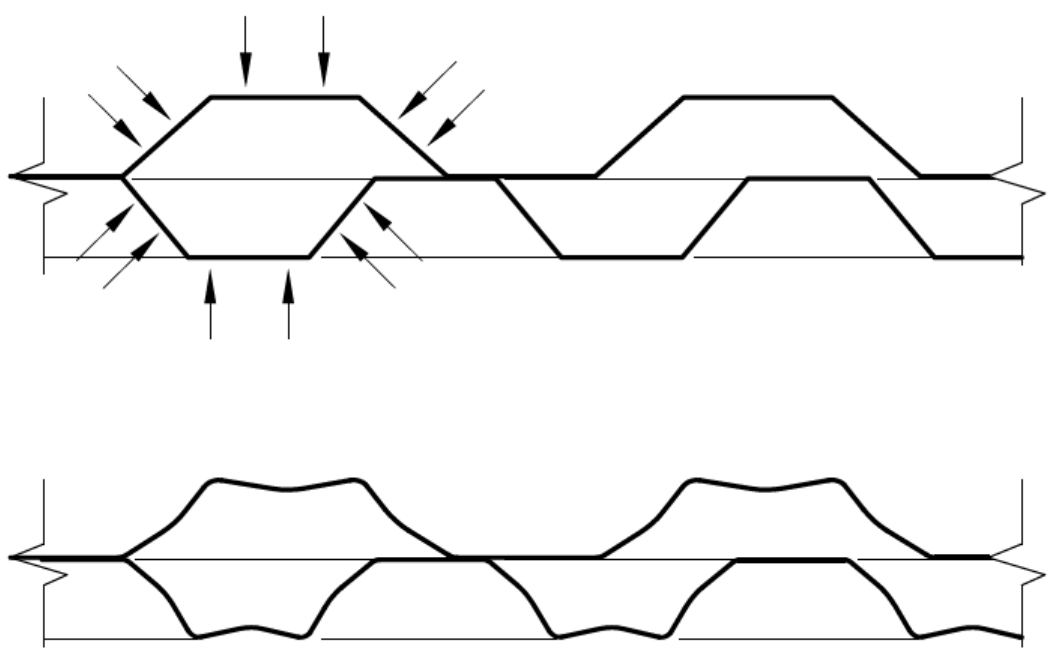

Fig. 6. Local channel collapse in plate heat exchanger.

Heatric notes in Reference 4, that, "The combination of low design strength (probably less than $10 \mathrm{MPa}$ at temperature) and relatively high design pressure (as a percent of design stress) will... limit the type of plate heat exchanger. Edge welded plate or any exchanger type with large unsupported areas will be mechanically unacceptable." We note that, while this may be true under high delta-P fluid applications, there are IHX applications with low pressure on both sides where simple edge-welded plate designs may be applicable., An example is a sodium-to-sodium heat exchange to an intermediate loop Plate type designs supported only on the edges are highly attractive for solving thermal stress problems since the layers cannot support any in-plane shear stresses except at welds, resulting in low thermal stresses over much of the plate area.

\subsection{UNIT CELL PLATE DESIGNS}

A rather different plate design approach has been taken by Ingersoll-Rand for gas turbine recuperators which can handle moderately high temperatures and moderate delta-Ps and still operate with low thermal stresses. This concept is being considered for recuperator service in the $\mathrm{sCO}_{2}$ plant cycle and for the IHX in NGNP, as described in References 17 and 18.

The original Ingersoll-Rand recuperator design concept is a brazed plate/fin heat exchanger operating in cross flow with open low pressure side edges. In this design, the high pressure (primary) compressor air is heated by low pressure turbine exhaust. The Ingersoll-Rand design is in use in commercial and military gas turbine recuperators to heat compressor air. They can handle moderately high temperatures and pressures, $530 \mathrm{C}$ and a delta-P of $1.5 \mathrm{MPa}$. The design is especially robust against demanding temperature transients.

The nuclear applications for the unit cell heat exchanger are proposed to be counter flow designs as shown in Fig. 7, Fig. 8 and Fig. 9 below. 


\section{Unit-Cell Construction Exploded View

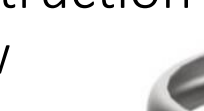

ôn'Brayton Energy uc

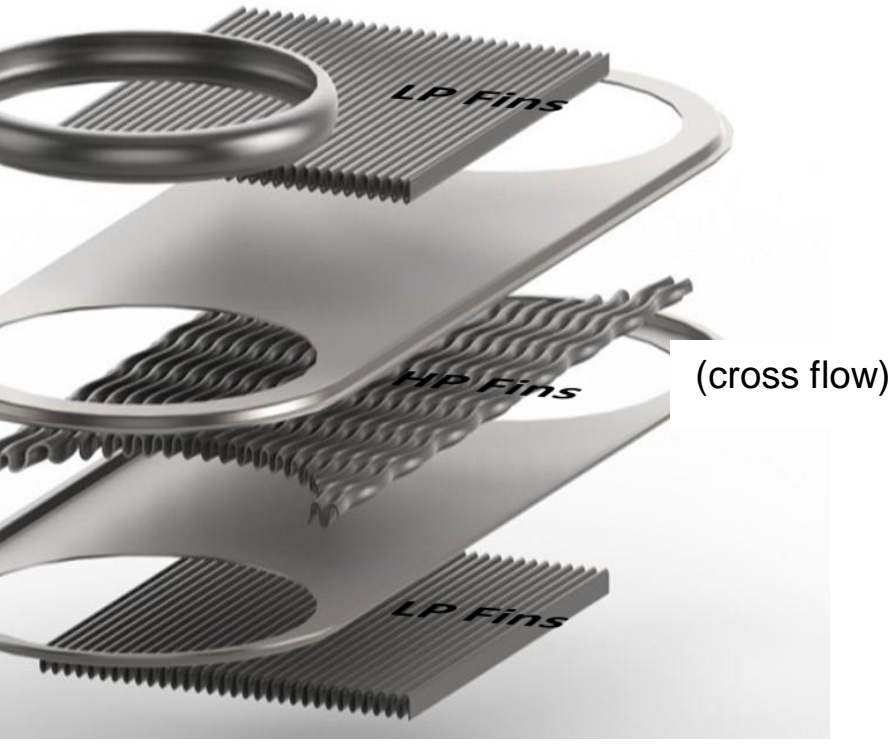

Fig. 7. Unit cell heat exchanger component parts. Reprinted with permission from Brayton Energy, LLC.

\section{Unit-Cell Construction}

Cutaway Fin-Fin Core

- Cells welded at rings only

- Slip-plane at adiabatic boundary between LP fins
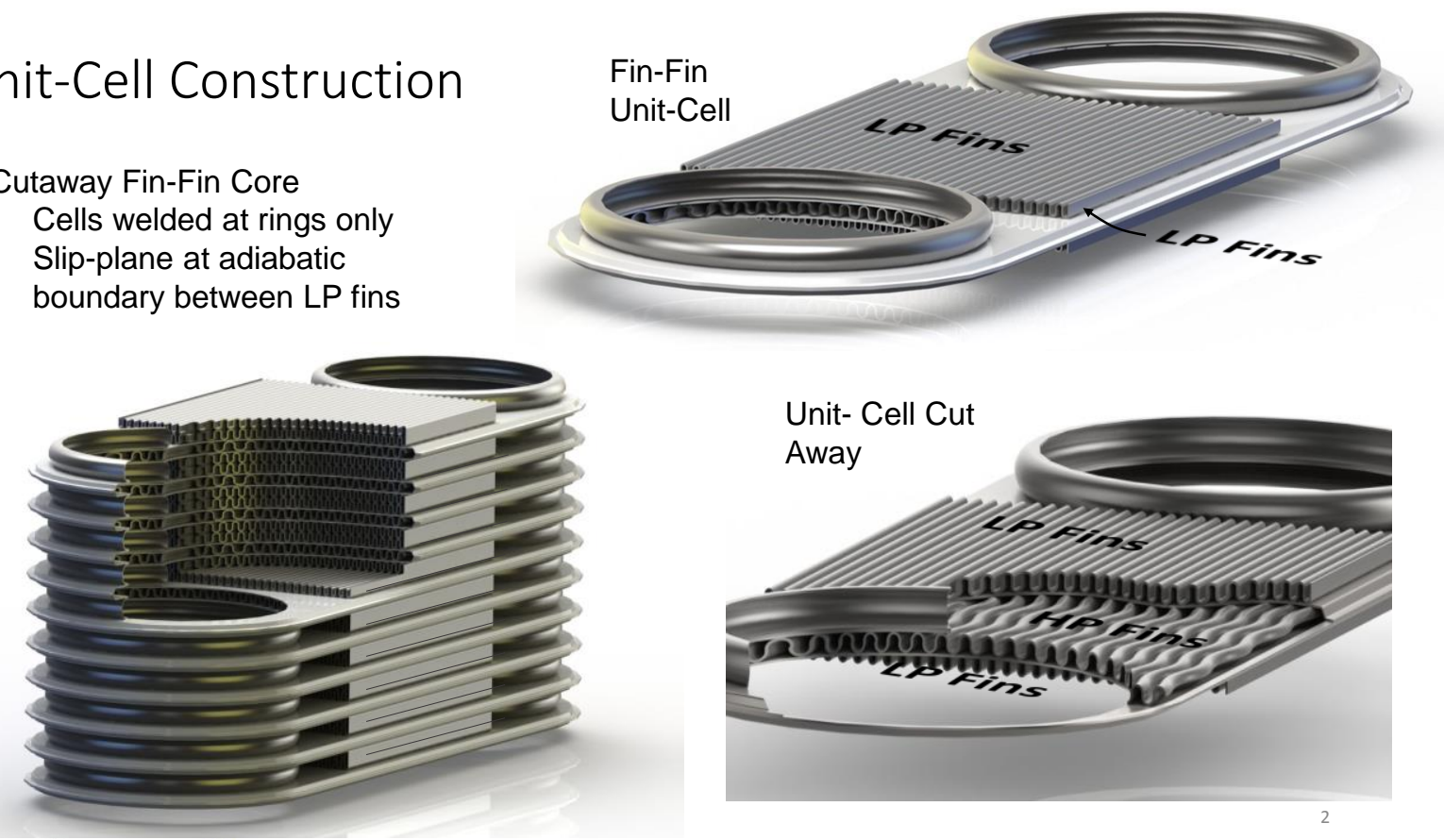

Fig. 8. Unit cell heat exchanger assembly. Reprinted with permission from Brayton Energy, LLC. 


\section{Unit-Cell Construction Flow Orientations}

\section{F̈rírayton Energy uc}

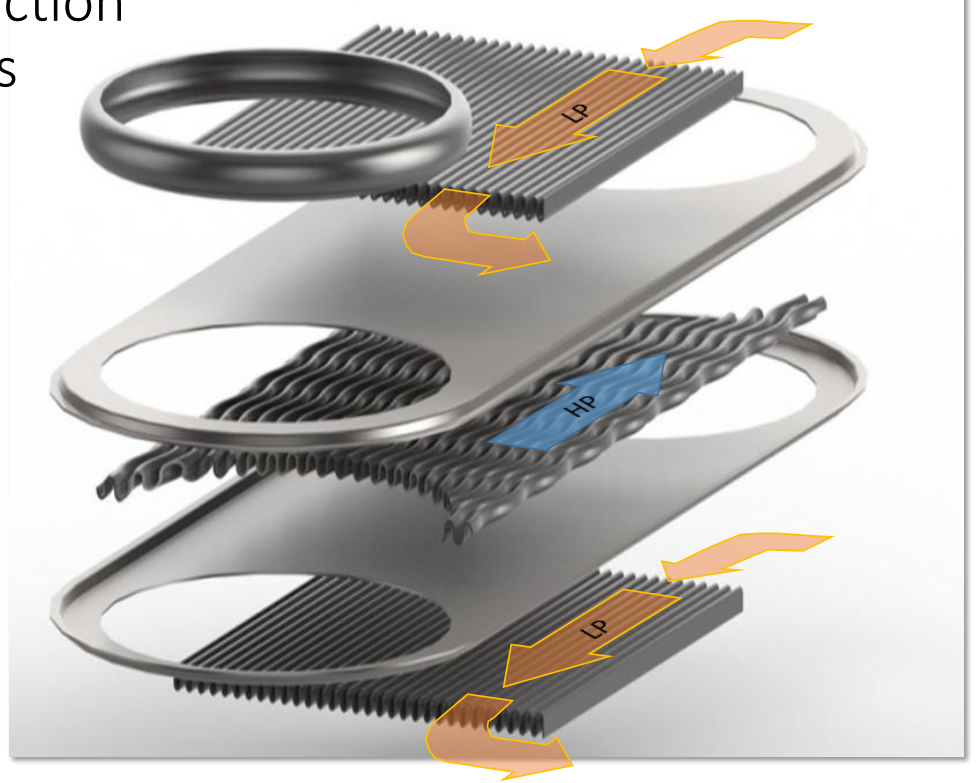

Fig. 9. Unit cell heat exchanger crossflow. Reprinted with permission from Brayton Energy, LLC.

The cells layers are connected by brazing or welding only at the high pressure manifolds shown above. This produces a stack of cells with much higher internal flexibility than the solid core described in Section 2.1.

The key to the design is the unit cell which consists of two partition plates supporting a single corrugated, high pressure cell fin row. Secondary side fins are brazed or bonded to the outside of the partition plates. The partition plates and pressure cell fin row are brazed or otherwise bonded to form a single layer, highpressure cell with attached secondary side fins. Pressure can be supported within the pressure cell layer without the aid of a strong back or cage. A single unit cell layer is shown in Fig. 10, below.

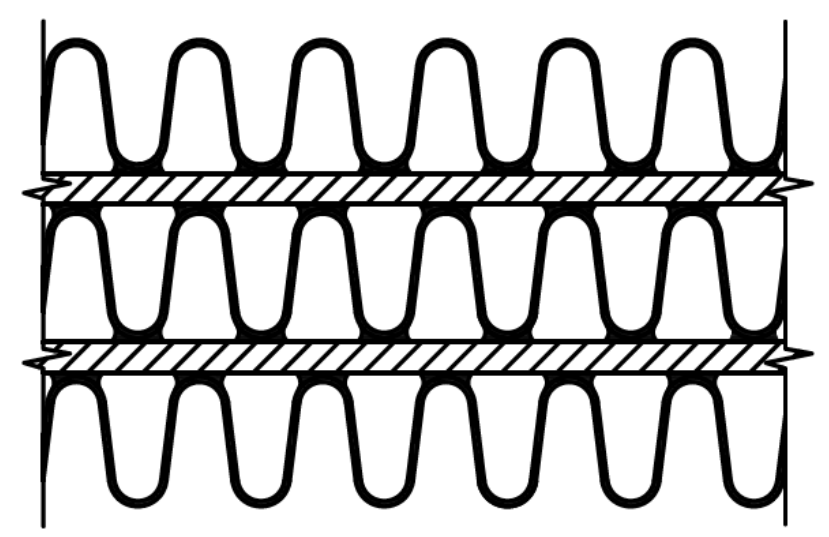

Fig. 10. Unit cell layer containing high pressure cell and low pressure external fins.

For a nuclear Brayton cycle, the working fluid might be high pressure ( 9 MPa), high temperature (800950C) helium. Normally, the delta-P between the primary and intermediate (secondary) loops is relatively small, about $0.5 \mathrm{MPa}$. But the unit cell design allows the heat exchanger to a handle loss-ofpressure transient in the secondary loop without primary rupture under the resulting high delta-P 
conditions. This capability is required by the Code (loss of pressure on one side) and which is unlikely to be achieved in simple edge-welded plate designs. The unit cell design concept might even be a good candidate for low pressure to high pressure heat exchange such as might be needed for a liquid sodium to high pressure fluid ( $\mathrm{sCO}_{2}$ Brayton cycle) plant. The sodium would occupy the secondary (low pressure) layers in the design, and the fluid the high pressure cell layers.

Some means must be provided for supporting the secondary pressure, and a means must be provided to seal the secondary side edges outside of the secondary inlets and outlets so as to direct the secondary flow over the plates in a counter flow direction, rather than the cross flow used by Ingersoll-Rand. This is shown in Fig. 11. Consequently, it appears the heat exchanger will require a containment vessel for the secondary gas or liquid and welded edges on portions of the cell-to-cell secondary side layers. A concave canopy type seal would probably be suitable to seal portions of the secondary side edges for counter flow operation while providing some cell-to-cell edge flexibility. We note the pressure cell flexibility could be further increased by periodically interrupting corrugated fin sections. Fin sections could also be periodically offset one-half the fin pitch to increase mixing (and pressure drop) and reduce thermal gradients due to flow maldistributions.

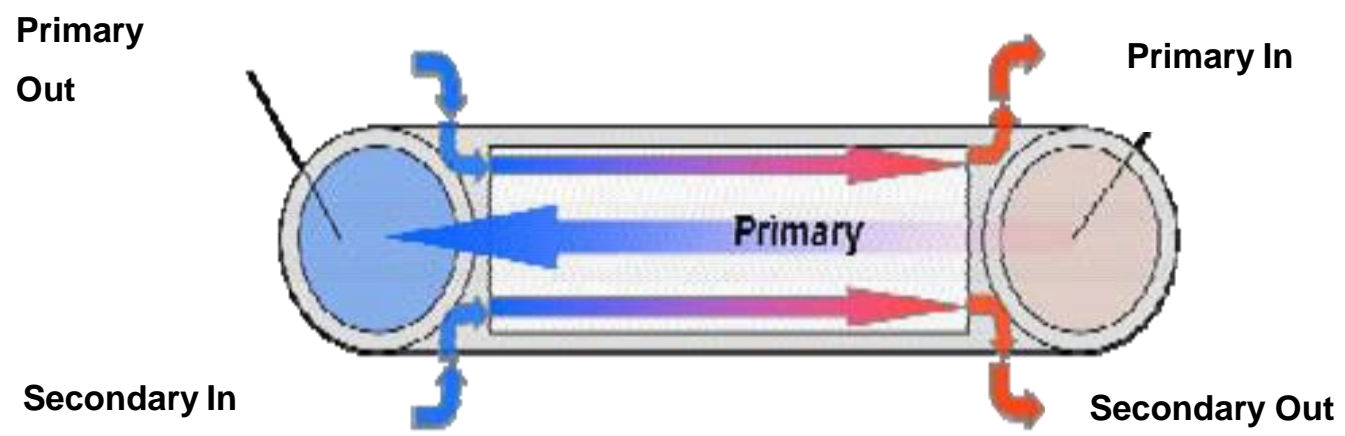

Fig. 11. Unit cell HX in counterflow operation. After Ref 18. Reprinted with permission,

As noted earlier, the Ingersoll-Rand service experience has been with brazed unit cell designs. The fabrication, inspection, and potential creep limitations of brazed designs described earlier in Section 2.1 affect this design as well, so another method of cell bonding will likely be required for nuclear service. Achieving higher pressures and Code certification may require going with diffusion bonded (i.e. welded) plate/fin structures and conventionally welded high pressure manifold layers. This bonding method is described in Section 2.4.

\subsection{DIFFUSION BONDED (DIFFUSION WELDED) DESIGNS}

A relatively recent development in compact heat exchanger design is the diffusion bonded (also referred to as "diffusion welded") printed circuit and formed plate design. Research interest in diffusion bonded heat exchangers for nuclear service has been high, and recent ASME Code activities have focused on the endorsement of diffusion bonding as a Code-approved heat exchanger joining technique. Heatric has had the most experience manufacturing diffusion bonded designs and holds an ASME Section VIII "U" stamp for their production. Other manufacturers, such as Vacuum Process Engineering (VPE) and Velocys are also developing diffusion bonded heat exchangers, and the VPE work is in collaboration with the Sandia National Laboratories for potential nuclear applications. Kobe Steel in Japan has also investigated diffusion bonding and has fabricated at least one U-stamped, stainless steel PCHE using this method. See Fig. 15a which was taken from Reference 5. 
Diffusion bonding is a solid state welding process that bonds two contacting surfaces (faying surfaces) through the application of heat and pressure in a vacuum. The process is performed at elevated temperatures but below the melting point and at moderate pressure (5-10 MPa or 700-1400 psi). The faying surfaces merge by a diffusion process as shown in Fig. 12.

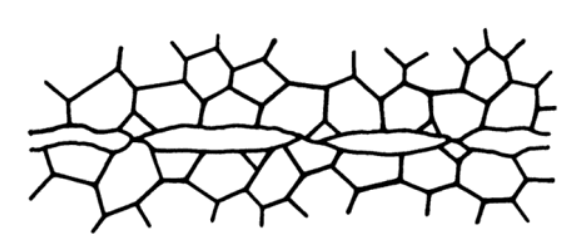

Initial Asperity Contact

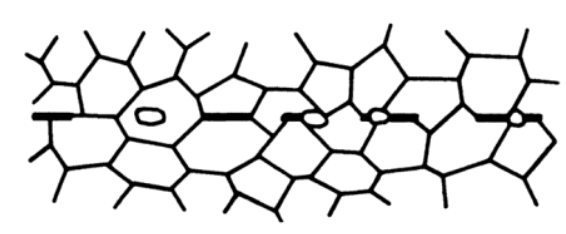

(B) Second Stage-Grain Boundary Migration and Pore Elimination

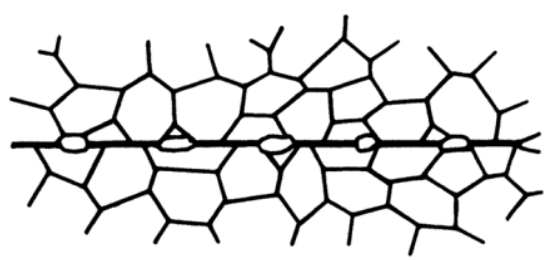

(A) First Stage-Deformation and Interfacial Boundary Formation

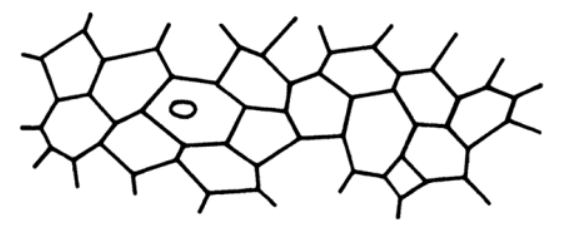

(C) Third Stage-Volume Diffusion Pore Elimination

Fig. 12. Diffusion bond recrystallization process. After Ref 1. Reprinted with permission.

In contrast to brazed joints where the braze alloy and its interaction with the base material affects joint strength, creep, and fatigue properties, the diffusion bonded joint is advertised to have base metal properties.

\subsubsection{Printed Circuit Heat Exchanger (PCHE)}

Diffusion bonding has facilitated the development of highly effective (high rate of heat exchange per unit volume) printed circuit heat exchanger designs with heat transfer surface-to-volume ratios (areal densities) approaching $2500 \mathrm{~m}^{2} / \mathrm{m}^{3}$, Reference 1. Since the diffusion bonded designs being considered are relatively new compared to the plate-fin and formed plate designs described in Sections 2.1, 2.2 and 2.3, some effort will be expended here to describe this heat exchanger. In this design, the flow channels are chemically etched into the partition plates themselves, and the plates are stacked and diffusion bonded to form the heat exchanger. This is shown in Fig. 13 and Fig. 14.

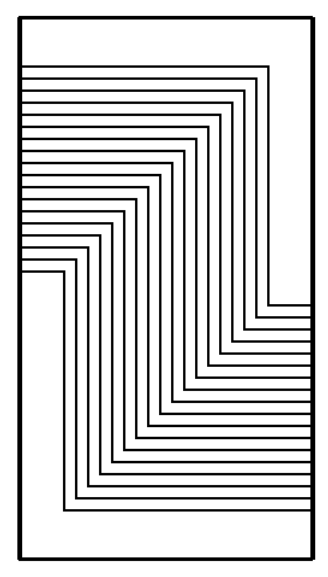

Fluid A

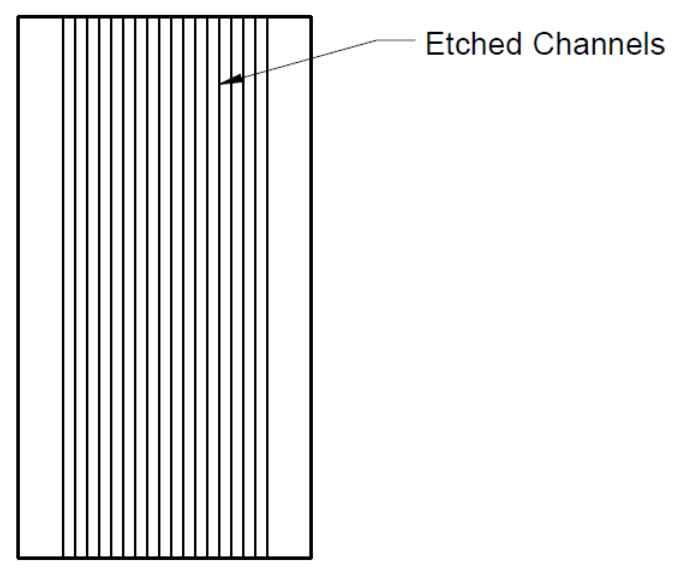

Fluid B 
Fig. 13. Chemical etch patterns for cross/counterflow PCHE.

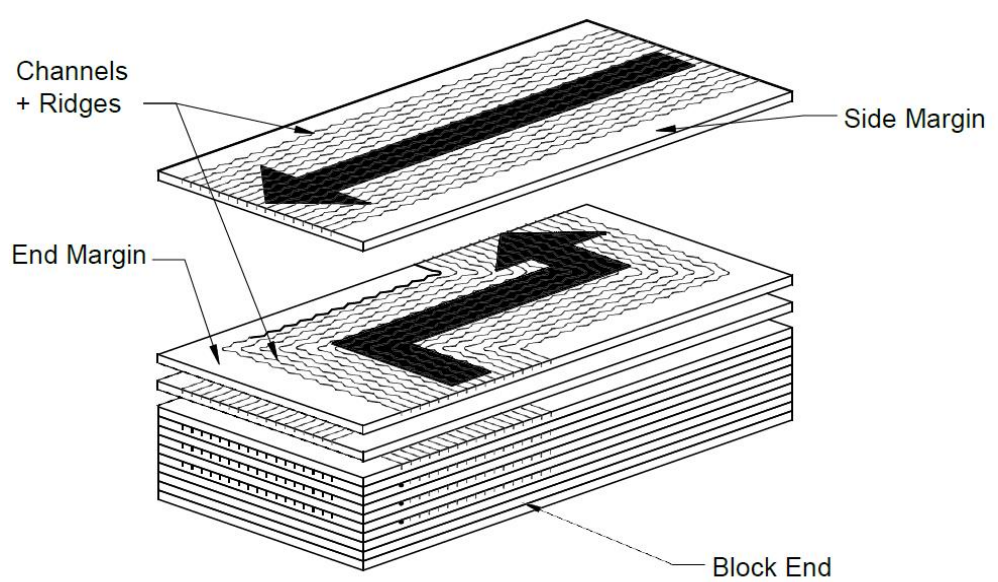

(a)

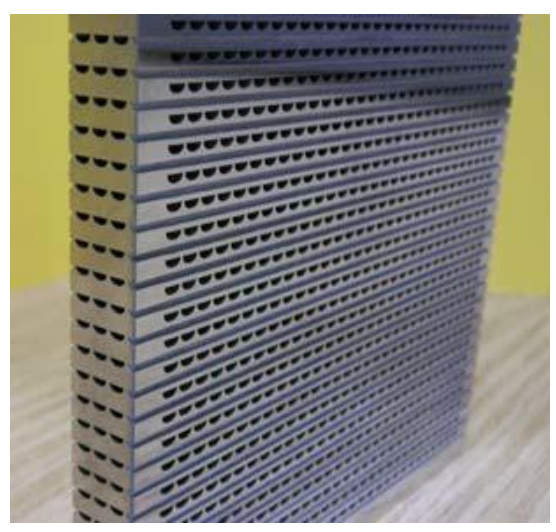

(b)

Fig. 14. (a) Plate stacking for bonding (cross/counterflow) (b) Bonded printed circuit core (cross flow subsection). After Ref 6. Reprinted with permission.

Once bonded, the heat exchanger becomes a monolithic block of metal since the weld fusion line between plates disappears as the grain structure recrystallizes during the diffusion process (See Fig. 12). The cross section of an actual bonded assembly is shown in Fig. 15, which shows typical semicircular etched channels and the bond area between the plates.

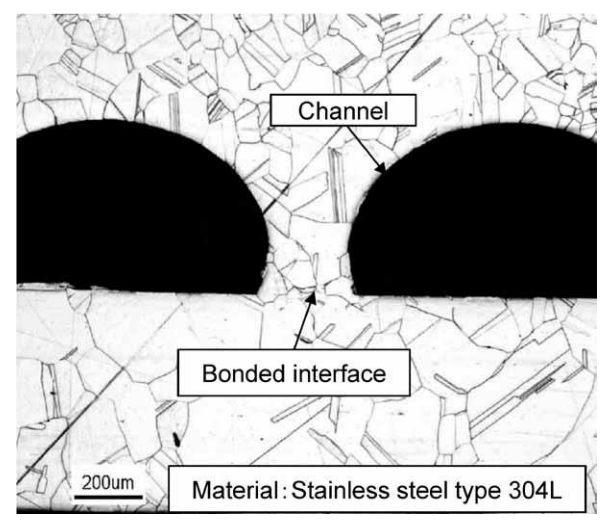

Fig. 15. Bonded section showing complete recrystallization. After Ref 5. Repeated with permission.

Heatric, Reference 7, shows various flow patterns that can be produced in the etched plates. For example:

- $\quad$ Counter flow with cross flow on the ends (as shown in Fig. 13 and Fig. 14)

- $\quad$ Simple cross flow (Fig. 16)

- $\quad$ Cross-counter flow (Fig. 17)

- $\quad$ Serpentine counter flow (Fig. 18) 

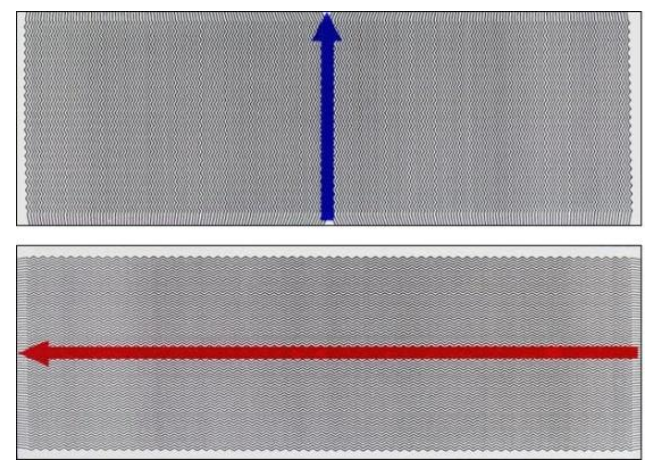

Fig. 16. Cross flow etching pattern. After Ref 7, Copyright 2010 by the American Nuclear Society, La Grange Park, Illinois. Reprinted with permission.
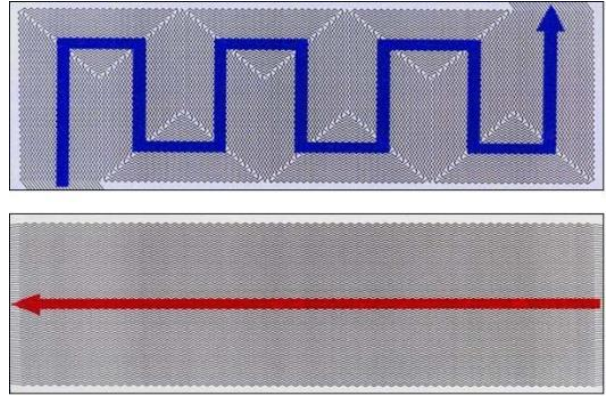

Fig. 17. Cross/counter flow channel etch pattern. After Ref 7, Copyright 2010 by the American Nuclear Society, La Grange Park, Illinois. Reprinted with permission.
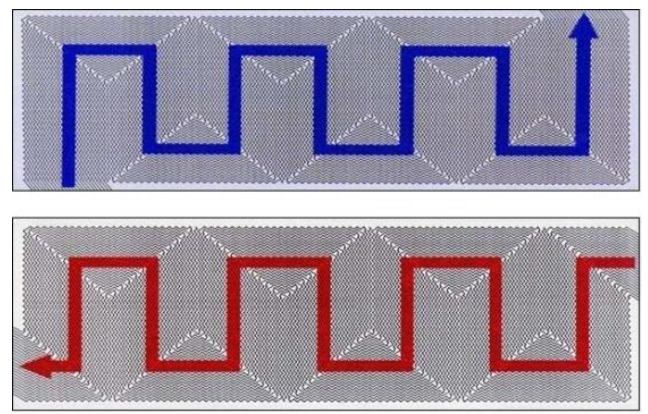

Fig. 18. Serpentine counter flow etch pattern. After Ref 7, Copyright 2010 by the American Nuclear Society, La Grange Park, Illinois. Reprinted with permission.

In some cases, internal porting can be designed into the plate stock by etching completely through the plates or headers, as shown in Fig. 19, similar to what is done for embossed plate laminae like those shown in Fig. 4. 


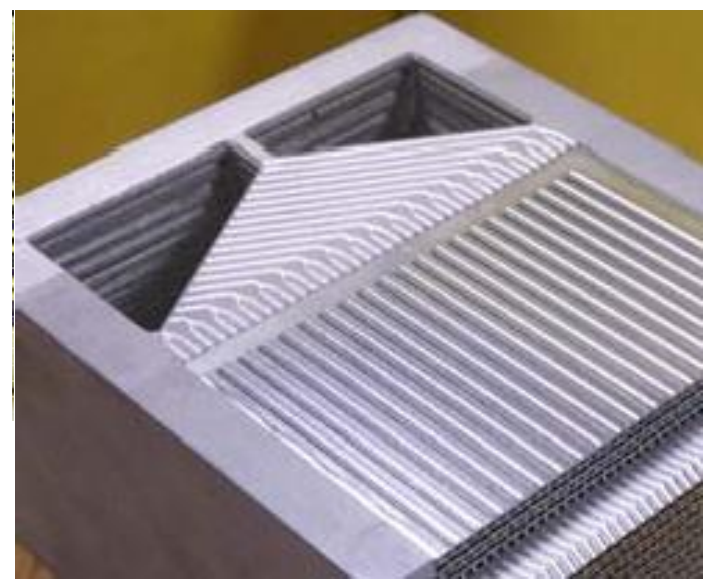

(a)

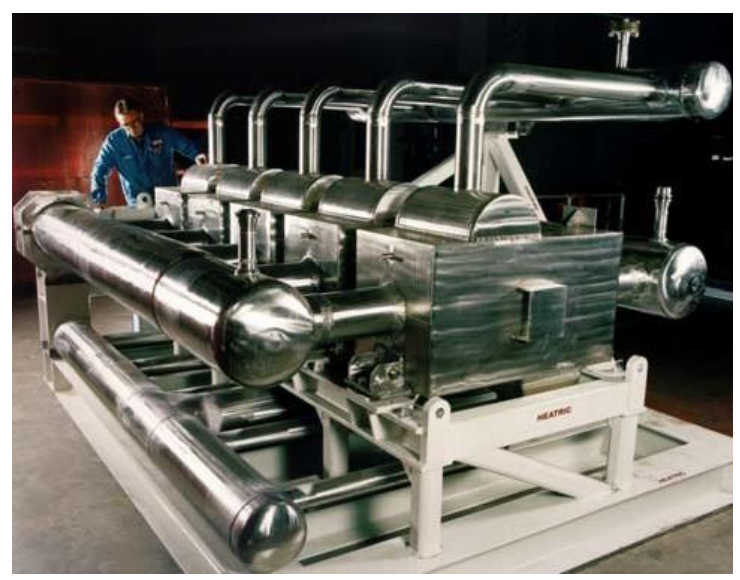

(b)

Fig. 19. (a) Plate stack showing buildup of internal headers. After Ref 7, Copyright 2010 by the American Nuclear Society, La Grange Park, Illinois. Reprinted with permission. (b) Finished multi-block heat exchanger containing external "D" headers and internal ported headers. After Ref 8, Copyright 2009 by the American Nuclear Society, La Grange Park, Illinois. Reprinted with permission.

The PCHE channels are roughly semi-circular and can vary in depth (depending on design) from about $0.1 \mathrm{~mm}$ to $2.5 \mathrm{~mm}$, but only the larger channels will be of practical interest for power service. The unetched ridges between channels form the "fins". Fin thickness depends on design pressure, allowable stress at temperature, and channel etch depth. The channel "wall" is the remaining unetched material above and below the channels. It is influenced by the channel width. Side and end margins, shown in Fig. 7, become the side walls of the diffusion welded block. The stack ends are the unetched plates above and below the etched stack which form solid end walls once the stack is diffusion bonded. Currently, Heatric can manufacture blocks with dimensions up to $0.6 \mathrm{~m} \times 0.6 \mathrm{~m} \times 1.5 \mathrm{~m}$, Reference 6 . If larger heat exchangers are required, multiple blocks can be welded together, as shown in Fig. 20, taken from Reference 7.

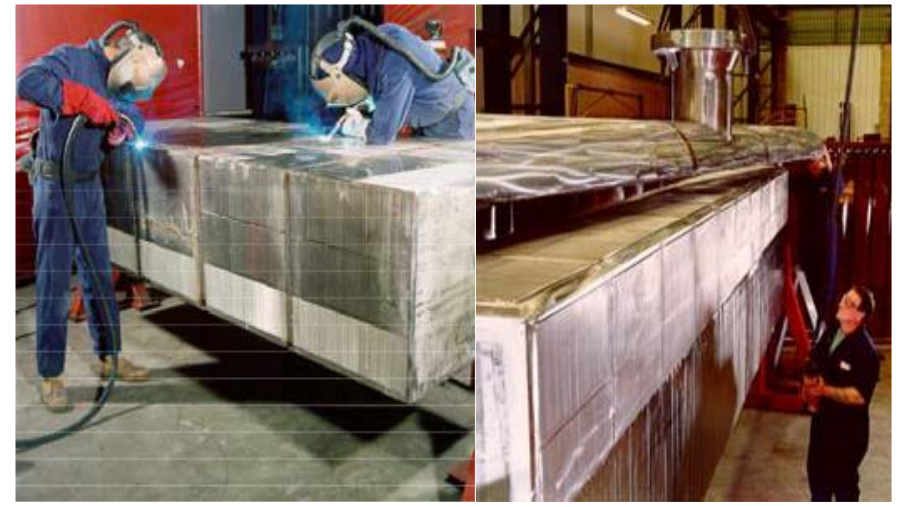

Fig. 20. Multi-block core during fabrication. After Ref 7, Copyright 2010 by the American Nuclear Society, La Grange Park, Illinois. Reprinted with permission.

PCHE blocks will usually have headers, nozzles, and flanges, as shown in Fig. 21 for a single block, and in Fig. 20 and Fig. 22 for a multiple block design. 


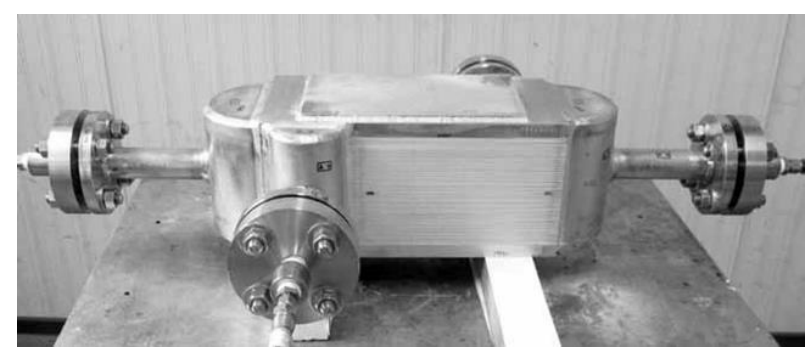

(a)

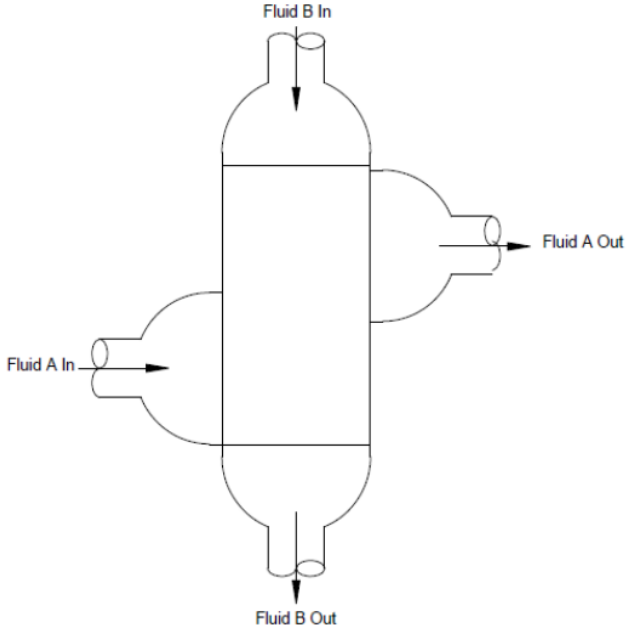

(b)

Fig. 21. (a) Section VIII U-Stamp PCHE with cross/counter flow configuration shown in Fig. 14a. After Ref 5. Reprinted with permission. (b) Configuration of flows and headers for cross/counter flow configuration in Fig. 14a.

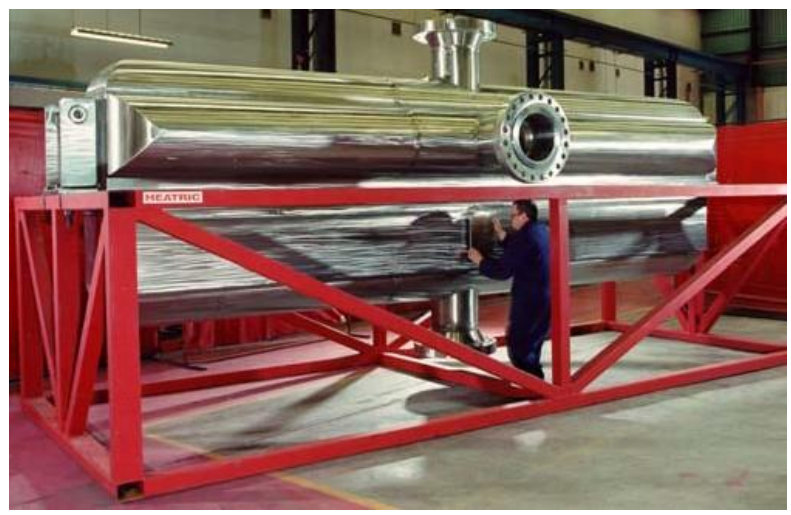

Fig. 22. Finished multiblock heat exchanger showing headers. After Ref 7, Copyright 2010 by the American Nuclear Society, La Grange Park, Illinois. Reprinted with permission.

\subsubsection{Formed Plate Diffusion Bonded Heat Exchanger}

The formed plate heat exchanger offers large channel size and material economy over the printed circuit approach, Reference 7. The construction is similar to the plate-fin brazed design shown in Fig. 1 but the core is diffusion bonded, rather than brazed. This design is useful for lower pressure applications like a sodium service. For high pressure applications like helium primary loop to helium intermediate loop, the printed circuit design is more suitable, at least from a primary stress standpoint. For service between low and high pressure systems like the sodium $/ \mathrm{SCO}_{2} \mathrm{SHX}$, a composite design can be used that is fabricated from alternating formed plate and printed circuit laminae.

A close-up view of the formed plate and printed circuit channels is shown in Fig. 23, from Reference 8. (As will be discussed in later sections, loads applied perpendicular to the weld joint must be evaluated based on a weld joint efficiency factor that is applied to the allowable stress.) A core containing both printed circuit and formed plate channels (composite heat exchanger) is shown in Fig. 24. 


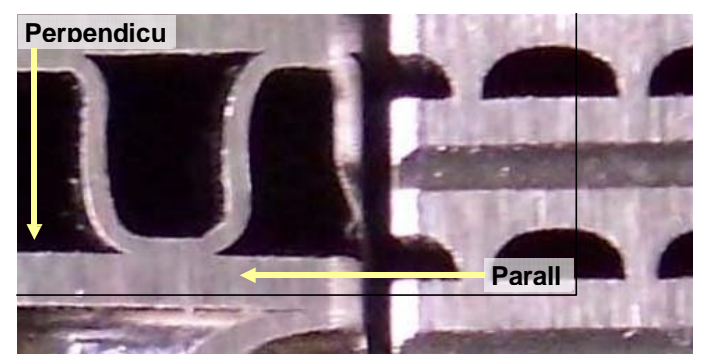

Fig. 23. Close-up views of diffusion-bonded formed plate (left) and printed circuit (right) channels. Arrows indicate loads perpendicular and parallel to the bond joint. After Ref 7, Copyright 2010 by the American Nuclear Society, La Grange Park, Illinois. Reprinted with permission.

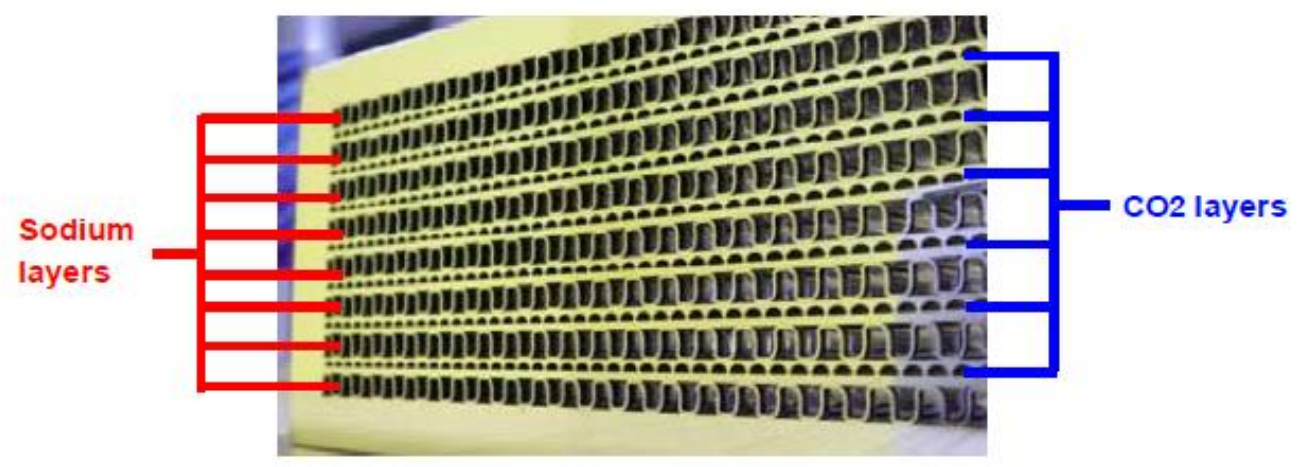

Fig. 24. Composite heat exchanger core with alternating layers of etched and formed plate channels. After Ref 7, Copyright 2010 by the American Nuclear Society, La Grange Park, Illinois. Reprinted with permission.

\subsubsection{Diffusion Bonded, Unit Cell Plate Heat Exchanger}

The unit cell plate heat exchanger design described in Section 2.3 can be adapted to diffusion bonding methods described for the composite heat exchanger design above. The "stack" for diffusion welding would consist of a single pressure cell with internal fins and its attached secondary fins. 


\section{CURRENT CODE STATUS}

Vacuum brazed plate-fin heat exchangers are covered by design rules in the ASME Code, Section VIII, Division 1 (U, U2, R stamps) along with Section IX weld procedure and welder qualification requirements for brazing. The strength properties of the braze alloy limit the upper temperature at which these designs can be used, and the basic plate-fin geometry limits service to moderate pressures. For those reasons and as noted earlier, the brazed designs are not being considered for high temperature nuclear service.

Edge-welded plate heat exchangers have long been part of the Section VIII of the ASME Boiler and Pressure Vessel Code.

Diffusion bonding (or diffusion welding) was added to the allowed Section IX welding processes ("DFW" welding) in the 2011 Addenda. Requirements for the diffusion bonding of microchannel heat exchangers were outlined in Code Case 2437-1 in 2005 and were incorporated directly in Section VIII, Division 1 in 2011 (in enhanced form) as Mandatory Appendix 42. The Appendix specifies bonding procedures and performance qualification tests. These are similar to the DFW requirements in Section IX.

Design, fabrication and inspection requirements for diffusion bonded microchannel heat exchangers were provided in 2009 in Code Case 2621-1. There are restrictions in the Code Case, as follows:

- The alloys for construction are limited to:

- $\quad$ SA 240, Type 304L stainless steel

- $\quad$ SA 240, Type 316L stainless steel

- $\quad$ SA 240, 2205 stainless steel.

- $\quad$ Bi-metallic bond joints between dissimilar alloys are prohibited.

- The vessels cannot be used for "lethal service;" that is, in service containing lethal substances.

The alloys listed in Code Case 2621-1 are not the same as those allowed for Class A construction in Section III, Division 5. Relevant alloys for high temperature reactor heat exchanger service that are already in Division 5 are Type $304 \mathrm{H}$ and $316 \mathrm{H}$ stainless steels and Alloy $800 \mathrm{H}$. None of the alloys in Code Case 2621-1 or in Division 5 can achieve the high temperature, long service life requirements for the hottest applications of the IHX, but Alloy $800 \mathrm{H}$ comes closest.

Based on reviews conducted by Heatric for candidate alloys for very high temperature service, Reference 10, nickel base Alloys 617 and 230 would be the top candidates for IHX and SHX service. This is consistent with the conclusions of DOE, and a DOE effort to qualify Alloy 617 for Section III, Division 5 applications is on-going.

The "lethal service" restriction may apply to the IHX and SHX. This is certainly true for the berylliumcontaining molten salts being considered as a reactor coolant, and it may apply to molten sodium or leadbismuth alloys. But getting past this restriction may be simplified if a design can be qualified for nuclear safety related service in the first place.

Heatric currently holds a U-stamp for diffusion bonded microchannel heat exchangers, and Kobe Steel in Reference 5 describes a stainless steel PCHE with a U-stamp they produced. It is shown in Fig. 21a. Heatric has produced an Alloy 617 printed circuit heat exchanger for INL testing. The authors understand that Sandia National Laboratories is working with Vacuum Process Engineering in California to produce 
a printed circuit Alloy 617 heat exchanger, and Velocys in Texas is considering a U-stamp for diffusion bonded heat exchanger designs. 


\section{DIFFUSION BONDING ISSUES}

The successful incorporation of the diffusion bonded compact heat exchanger in high temperature in Class A or Class B nuclear service relies on the ability of the manufacturer to consistently and reliably produce core stacks with high quality diffusion welds. Since it is impractical to inspect each of the hundreds of thousands of welds in a core stack, component quality will depend on a good understanding of the essential welding variables and their strict control.

As touched upon earlier, diffusion bonding is a solid state joining process that uses moderate contact pressure between surfaces at a high temperature in a vacuum or controlled atmosphere to promote atom diffusion across the interface. A successful bond undergoes recrystallization of grains at the bond interface. If the process is carefully controlled, the diffusion bonded joint achieves base material properties. Some of the welding parameters for diffusion bonding are kept proprietary by the manufacturers, but some obvious ones include time, pressure, temperature and atmosphere.

The specific Section IX DFW welding "essential variables" controlled during weld procedure qualification are listed in Section IX and in Section VIII, Appendix 42. They include the following:

- $\quad$ Material grade

- $\quad$ Material sheet finish (smoothness)

- $\quad$ Material surface preparation

- $\quad$ Bonding temperature and time

- $\quad$ Bonding atmosphere

- $\quad$ Block compression (i.e. pressure)

- $\quad$ Post-bond heat treatment

Since little is publicly known about details of the process controls required in each of these areas, some effort by DOE/ASME to independently understand the diffusion bonding process is warranted, especially for some of the newer nickel base super alloys like Alloy 617. A summary of the current public understanding of the essential variables is presented in Reference 1. A few important observations from that reference are as follows:

- Material thermodynamics - The thermodynamics of the base metal (melting point, creep rate, recrystallization dynamics) will determine the required temperature, pressure and time for bonding.

- $\quad$ Material chromium content - Corrosion resistant materials like the stainless steels, Alloy 800 and the nickel base super alloys like Alloy 617 contain high levels of chromium (>15\%) as an alloying element. Chromium forms a protective oxide at ambient temperatures and above that provides corrosion resistance. Unfortunately, this oxide is not very soluble in the base metal, and it inhibits diffusion and recrystallization at the bond interface. Even if the oxide is stripped off in a pickling bath prior to bonding, sheet surfaces quickly re-oxidize in the high temperature vacuum press environment which usually contains residual water vapor. One key to successful diffusion bonding of these alloys is the method used to control chromium oxides.

- $\quad$ Surface preparation - A common technique for protecting surfaces from oxidation is to electroplate a thin $(\sim 1 \mu \mathrm{m})$ nickel layer on sheet surfaces after they have been stripped of oxides by pickling or 
by reverse polarization of the plating electrodes. The nickel oxides that form on the plated nickel surface are soluble in the nickel and the underlying base metal and diffuse away from the joint interface during bonding. Eventually, the nickel itself diffuses into the parent material and disappears, as reported in Reference 1.

- $\quad$ Surface finish - The smoothness of the plate surface affects the local contact area in the bond and the height of asperities that must be absorbed during the bonding process (see Fig. 12). This in turn, affects the required stack compression and the time required for joining without producing residual voids.

- $\quad$ Stack compression - The required pressure to make a diffusion bond depends on surface finish, as noted above, the temperature used for bonding and the base metal primary creep rate at that temperature and pressure. The formed plate designs used in composite heat exchangers will require sufficient pressure to evenly contact all formed fin tops in a layer during the bonding process, and these can vary slightly in height and fin top flatness. At the same time, too much pressure could buckle the fins due to creep.

Current DFW procedure and performance qualification requirements specify that mechanical tests be performed on diffusion bonded blocks containing unetched (no channels) laminae of the standard sheet material used in the welding. Some reduction in strength is expected after bonding due to the reduction in cold work dislocation density at the bonding temperature. This was reported by Heatric in Reference 8 for 316L stainless steel sheet, but minimum Code mechanical properties and creep strength were still met after bonding. Similar results were observed by Kobe Steel in Reference 5. Preliminary work by Heatric on Alloy 617, reported in Reference 12, suggests the alloy still meets Code minimum properties after the bonding thermal cycle.

The bonding process involves heating to above $1000^{\circ} \mathrm{C}$, which creates the potential for recrystallization of the entire cross section, not just at the bond line. Gross recrystallization will more dramatically affect the mechanical, fatigue and creep properties of the bonded stack. Since the sheet material will likely be cold finished at the mill to meet stringent thickness and surface finish requirements, it will likely undergo a 5$20 \%$ cold reduction pass as a finishing operation. Because of the cold work, rapid grain growth during bonding is possible, producing a coarse microstructure which has a negative impact on strength, creep strength and resistance to cyclic fatigue. Care must be taken to avoid cold finishing levels in the sheet stock that could lead to excessive grain growth during bonding process.

Finally, there has been recent work reported in the literature regarding the use of "transient liquid phase" brazing for compact heat exchangers, Reference 2. In this method the core is brazed with a nickelphosphorous or nickel-boron braze alloy which melts at a relatively low temperature. The liquid braze alloy fills in asperities and promotes diffusion at the bond line. Under pressure and long hold times, the braze alloy eventually diffuses and dilutes into the base metal leaving a diffusion bond with no remaining braze alloy.

It is tempting to consider using an electroless nickel plating on the lamina sheets as a method to apply the braze alloy and also to prevent chromium oxide formation. Electroless nickel coatings can be made with the $9-11 \%$ phosphorous levels used in braze alloys. Unfortunately, in the work reported in Reference 2, the phosphorous was found to produce high levels of nickel and molybdenum phosphides in Alloy 617 near the bond line. The rate of diffusion of the phosphorous was slow and phosphorous levels stayed high near the bond line. This produced an inhomogeneous microstructure with unknown strength, creep and fatigue properties. Because of this, the use of electroless nickel containing high phosphorous levels cannot be recommended.

It is not clear from a review of the open literature if sufficient public understanding of the diffusion bond (DFW weld) essential variables exists to accept this method for nuclear service. As a case in point, in 
recent work at the Ohio State University there were bond failures in mechanical property test specimens removed from an Alloy 617 bond stack, Reference 11. The bonds showed evidence of oxide contamination and had low strength and no ductility. A bond cross section from the stack is shown in Fig. 25, taken from Reference 11. The authors reported that the stack sheets had been nickel electroplated, but this was obviously insufficient to control oxides. Clearly, more work needs to be done to determine how the diffusion bonding process can be made robust and able to accept variations in the essential variables described above, and maybe others. This work is required to build confidence in the DFW process and should be published in the open literature for peer review and potential incorporation in the Section III rules.

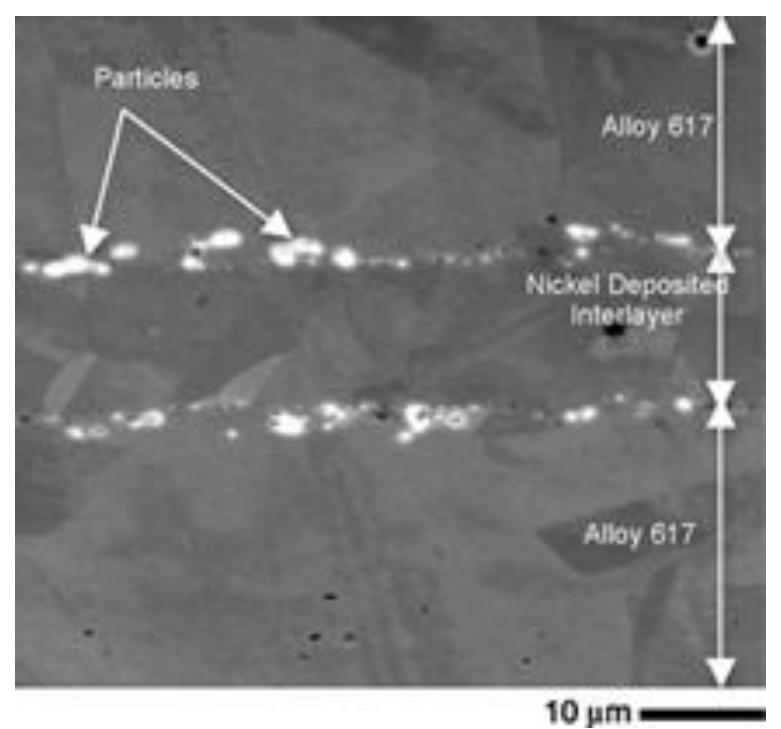

Fig. 25. Diffusion bond showing residual particles (probably oxides). After Ref 11. Reprinted with permission from Elsevier. 


\section{MECHANICAL DESIGN APPROACHES FOR MICROCHANNEL HEAT EXCHANGERS}

\subsection{ASME BPV CODE SECTION VIII DIVISION 1}

Code Case 2621-1 allows the construction of diffusion bonded microchannel heat exchangers to Section VIII, Division 1 rules, but with restrictions on the materials of construction and the limitation of applicability to non-lethal service, as described earlier. Heatric provides a detailed description of their mechanical design process for the channels and headers in Reference 6 . The process is based on the rules for non-circular vessels in Mandatory Appendix 13. MIT, Reference 13 and INL, References 1 and 14, have published channel designs based on the method of Hesselgreaves which is mathematically equivalent to the Heatric method for determining the channel pitch but differs from that approach for determining the total thickness of the etched plate. A brief description of these "design by rule" approaches is provided below.

Note: Extensive work has been done on the thermal performance of the heat exchangers, as well, but this work is not ASME Code related and will not be discussed in this paper. See References 1, 6 and 14 for examples of thermal performance calculations for compact heat exchangers.

The mechanical design of a printed circuit heat exchanger (PCHE) consists of setting the dimensions of the various components shown in Fig. 14, as follows:

- $\quad$ Unmilled ridge width between channels (influenced by the channel depth and plate gauge)

- $\quad$ Plate gauge (influenced by the channel depth and width)

- $\quad$ Side margins (influenced by header thickness and the attachment welds)

- $\quad$ End margins (influenced by header thickness and the attachment welds)

- $\quad$ Block ends (influenced by the thickest of the headers)

\subsubsection{Channel Design}

A printed circuit heat exchanger block contains numerous channels embedded in a solid matrix. A micrograph of a block cross section is shown in Fig. 26.

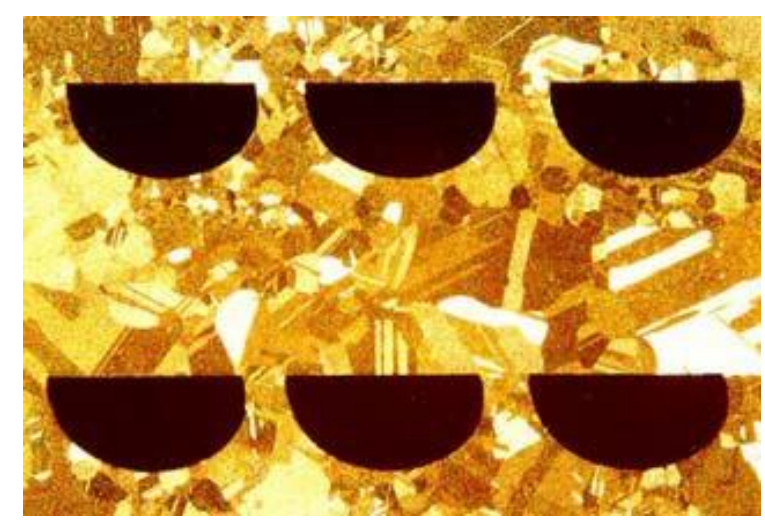

Fig. 26. Properly bonded core (crossflow section). After Ref 9, Copyright 2008 by the American Nuclear Society, La Grange Park, Illinois. Reprinted with permission. 
This array is shown schematically in Fig. 27 along with a simplified rectangular channel configuration which Heatric uses in design. Heatric models a row of channels as a rectangular vessel with multiple stay plates. The applicability of this simplification to the formed plated diffusion bonded composite designs and corrugated fin designs described earlier is obvious.

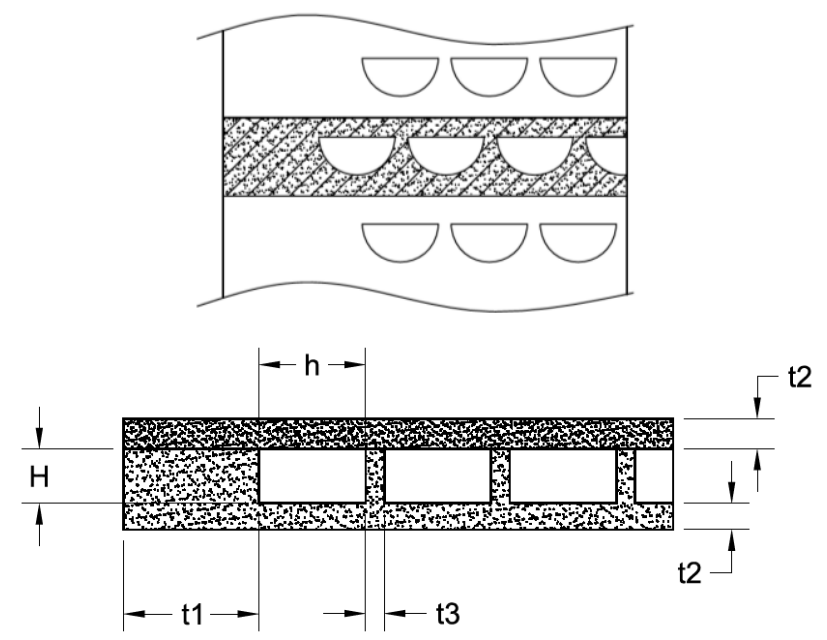

Fig. 27. Schematic of etched channel design (above) and simplified rectilinear model (below). After Ref 6 . Reprinted with permission.

The side margins (Fig. 7) have width $t_{1}$ in Fig. 27, and this becomes the side wall thickness in the bonded core. The unmilled regions between channels are represented by the stay plates with thickness $t_{3}$. The total thickness of the milled plate that forms a lamina in the core stack is $\mathrm{H}+\mathrm{t}_{2}$ in the figure. INL, in Reference 1, notes that this rectangular vessel simplification is conservative, since material is removed in the model compared to the semicircular channel shape. In summary, we have:

$$
\begin{aligned}
& \mathrm{h}=\text { channel width } \\
& \mathrm{H}=\text { channel depth } \\
& \mathrm{t}_{1}=\text { edge width } \\
& \mathrm{t}_{2}=\text { wall thickness of rectangular vessel } \\
& \mathrm{t}_{3}=\text { ridge or stay thickness }
\end{aligned}
$$

The rules of Section VIII, Division 1 are limited to load controlled stress limits under design conditions. The primary membrane and primary bending stresses due to internal pressure are combined and compared to the Section II, Part D allowable stress, S, for the design temperature. For sections loaded perpendicular to the diffusion bond (see Fig. 23), the allowable stress is reduced by an efficiency factor, E, of 0.7. While Heatric does not say, this is probably because the individual diffusion bonds cannot be inspected. Thus, the membrane stress must remain below $\mathrm{S} \times \mathrm{E}$ and the total membrane plus bending stress must remain below $1.5 \times \mathrm{S} \times \mathrm{E}$.

The thickness $t_{1}, t_{2}$, and $t_{3}$ can be determined from Section VIII, Division 1 rules in Appendix 13 for the multiple stayed, rectangular vessel, as follows:

For $\mathrm{t}_{1}$ :

$$
\mathrm{S}_{\mathrm{m}}=\frac{P h}{2 t_{1}}
$$


$\mathrm{S}_{\mathrm{b}}=\frac{P c}{24 I_{1}}\left(2 h^{2}-3 H^{2}\right)$ at the channel mid height

$\mathrm{S}_{\mathrm{b}}=\frac{P h^{2}}{12 I_{1}}$ at the corner intersection of $\mathrm{t}_{1}$ with $\mathrm{t}_{2}$,

We assume $t_{1} \gg t_{2}$, and note that:

$$
\begin{aligned}
& \mathrm{P}=\text { design pressure } \\
& \mathrm{S}=\text { design stress allowable } \\
& \mathrm{c}=\text { distance from neutral axis to extreme fiber } \\
& \mathrm{c}=\mathrm{t}_{1} / 2 \\
& \mathrm{I}=\text { moment of inertia } \\
& =\mathrm{t}_{1}{ }^{3} / 12 \\
& \mathrm{~S}_{\mathrm{T}}=\mathrm{S}_{\mathrm{m}}+\mathrm{S}_{\mathrm{b}}
\end{aligned}
$$

For $\mathrm{t}_{2}$ :

$$
\begin{aligned}
& \mathrm{S}_{\mathrm{m}}=\frac{P h}{2 t_{2}} \\
& \mathrm{~S}_{\mathrm{b}}=\frac{P h^{3} c}{12 I_{2}} \text { at the stays, } \mathrm{t}_{3} \text { and at } \mathrm{t}_{1} \\
& \mathrm{I}_{2}=\frac{t_{2}{ }^{3}}{12} \text { and } \mathrm{c}=\frac{t_{2}}{2} \\
& \mathrm{~S}_{\mathrm{T}}=\mathrm{S}_{\mathrm{m}}+\mathrm{S}_{\mathrm{b}}
\end{aligned}
$$

For $t_{3}$ :

$$
\begin{aligned}
& \mathrm{S}_{\mathrm{m}}=\frac{P h}{t_{3}} \\
& \mathrm{~S}_{\mathrm{b}}=0 \text { (all channels in the plane are at the same pressure) } \\
& \mathrm{S}_{\mathrm{T}}=\mathrm{S}_{\mathrm{m}}+\mathrm{S}_{\mathrm{b}}
\end{aligned}
$$

Note that for this method, the design pressure is accommodated entirely; pressure in adjacent channel layers above and below this one is assumed to be 0 psig, the same as is assumed outside the core block (outside $\mathrm{t}_{1}$ ).

INL, Reference 1, and MIT, Reference 14, take a somewhat less conservative approach for determining $\mathrm{t}_{2}$. The lamina plate thickness is assumed to be the outer radius of a thick-walled cylinder, and the inner radius is set by the semicircular channel radius, as shown in Fig. 28.

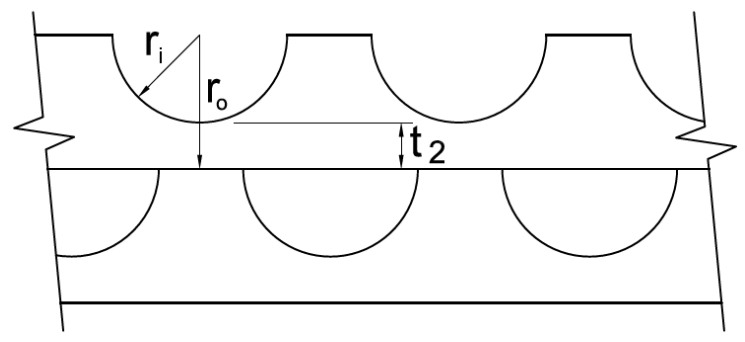

Fig. 28. Thick-walled cylinder model for sizing t2. 
Note that $r_{o}-r_{i}$ is $t_{2}$. The maximum stress is

$$
S_{m}=\frac{P}{2}\left(\frac{r_{o}^{2}+r_{i}^{2}}{r_{o}^{2}-r_{i}^{2}}\right)
$$

which effectively determines $t_{2}$. This approach leads to a slightly less conservative core design compared to the Heatric approach.

\subsubsection{Header Design}

Heatric assumes the " $D$ " headers are a cylindrical vessel with a diametrical stay, which is the block itself. They note that the header thickness is driven by the membrane stress, rather than the bending stress.

$$
\begin{aligned}
& S_{m}=\frac{P R}{t}, \mathrm{~S}_{\mathrm{b}} \text { is small } \\
& \text { where } \\
& \mathrm{P}=\text { design pressure } \\
& \mathrm{R}=\text { inner radius of the " } \mathrm{D} \text { " header } \\
& \mathrm{t}=\text { header wall thickness }
\end{aligned}
$$

As pressure increases, the required header thickness increases which requires greater side and end margins and block end heights (Fig. 14) to accommodate the header welds. For very high pressures, "D" headers become impractical and ported lamina plates, as shown in Fig. 19, are required to provide internal header flow.

\subsection{ASME BPV CODE SECTION III}

To the authors' knowledge, no outline of detailed design considerations for compact heat exchangers in nuclear service has been published. Some attempt to do so will be presented here based on the obvious design differences between Section VIII, Division 1 Rules and those in Section III, Division 5, Subsection $\mathrm{HB}$, Subpart B for safety Class A service. A brief look at Class B rules in Section III, Division 5 will also be presented.

\subsubsection{Section III, Division 5, Subsection HB, Subpart B Design for Class A Service}

Safety-related Class A rules typically apply to the design and construction of components in the reactor primary loop. This includes the IHX. The approach to stress analysis and stress allowable is more sophisticated than that in Section VIII, Division 1. Some differences are:

- In addition to a load controlled stress allowable for design conditions (similar to that described above for Section VIII rules), primary membrane and linearized bending stresses must meet separate limits for Service Level A and B, C and D conditions, representing normal operation, expected upsets, upsets requiring shutdown and inspection and low probability accidents, respectively.

- $\quad$ Stress and deformation limits exist based on primary and secondary (thermal) stresses as they affect total strain, cumulative creep damage, creep ratcheting, thermal ratcheting, buckling and cyclic fatigue. The last requires the determination of peak stresses in addition to linearized membrane and bending stresses. Thermal stresses, fatigue and explicit creep deformation and rupture life limits are not currently considered in the Section VIII design methodology described earlier. 
The Section III analysis of the heat exchanger is complex because there are two scale lengths important to stresses generated by mechanical loads and thermal gradients. On the millimeter scale are the channels and channel walls which contain the pressure load and which will exhibit very rapid thermal response to fluid temperature changes. On the macroscopic scale there are several parts of the heat exchanger that contain pressure and interact thermally: the core, sidewalls, end walls, block ends, side wall perforated sections and manifolds. Importantly, the core and perforated sections of the side walls will more rapidly respond to thermal transients than the slower responding walls and manifolds. This arrangement has the potential for generating large thermal stresses. The macroscopic components of the heat exchangers are shown in Fig. 29.

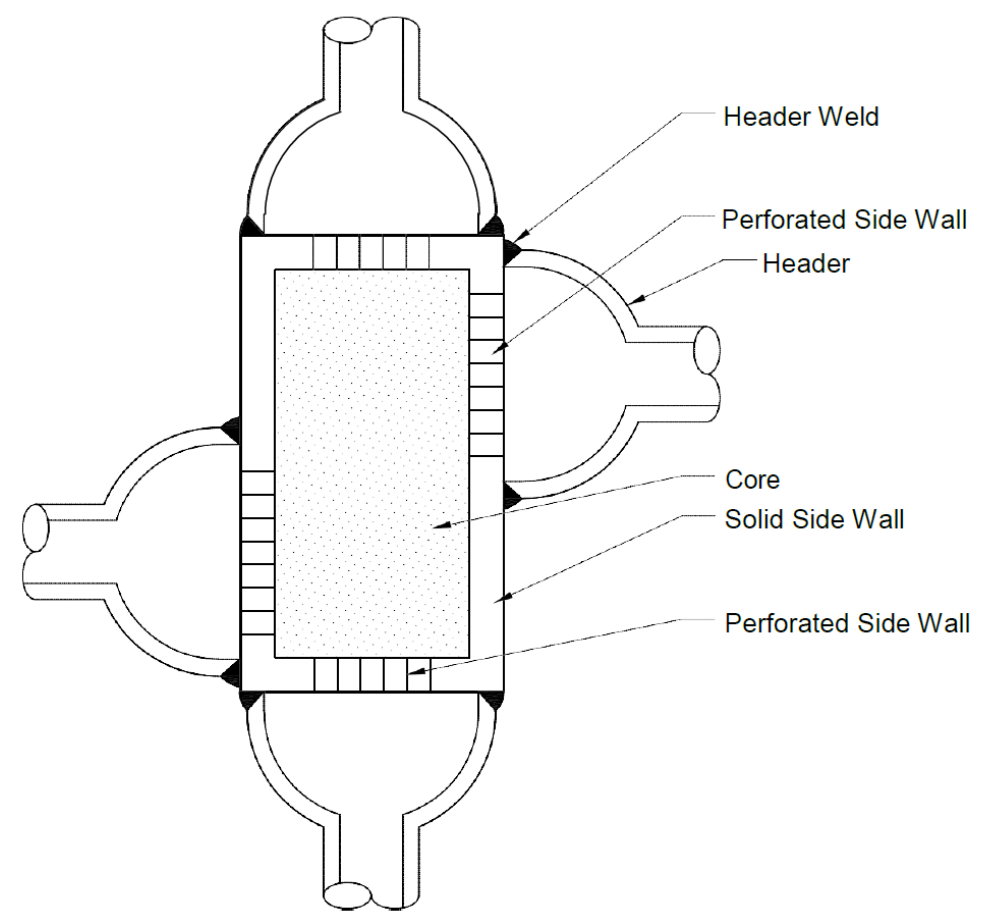

Fig. 29. Major components of the compact heat exchanger.

\subsubsection{Load Control Stress Allowables}

\section{Channel Sizing}

We can start the Section III analysis at the microchannel scale where channel dimensions are set. The first step is to determine the thermal performance requirements of the heat exchanger based on thermohydraulic models. Once the basic thermal performance and pressure drop requirements are established, the basic channel dimensions (based on hydraulic diameter and channel length) and flow pattern (cross flow, counter flow, etc.) can be set.

For the mechanical sizing analysis, channel size (rectangular formed plate designs or semicircular etched channels for printed circuit designs) is calculated based on thermal and pressure drop analysis, while the channel pitch and lamina plate thickness can be determined from the design condition allowable stress criteria in Division 5, Subsection HB, Subpart B:

$$
\begin{aligned}
& \mathrm{P}_{\mathrm{m}}<\mathrm{S}_{\mathrm{o}} \\
& \mathrm{P}_{\mathrm{L}}+\mathrm{P}_{\mathrm{b}}<1.5 \mathrm{~S}_{\mathrm{o}}
\end{aligned}
$$


where

$\mathrm{P}_{\mathrm{m}}=$ primary membrane stress

$\mathrm{P}_{\mathrm{L}}=$ local primary membrane stress (equals $\mathrm{Pm}$ away from discontinuities)

$\mathrm{P}_{\mathrm{b}}=$ linearized primary bending stress

$\mathrm{S}_{\mathrm{o}}=$ stress allowable in ASME BPV, Section II, Part D. $\mathrm{S}_{\mathrm{o}}$ is temperature dependent and based on 100,000-hr creep rupture data.

The design temperature and pressure are used for this evaluation, and the simplified methods for establishing the primary stresses described in the Section VIII methodology earlier, is perfectly acceptable for use here.

Of course, explicit formed plate or semicircular channel finite element models can be constructed to evaluate these stresses. Sections can be taken through various points around the channels and stresses linearized to compare with the design condition allowable above. A typical finite element model is shown in Fig. 30, along with the pressure stress results for another channel shape.

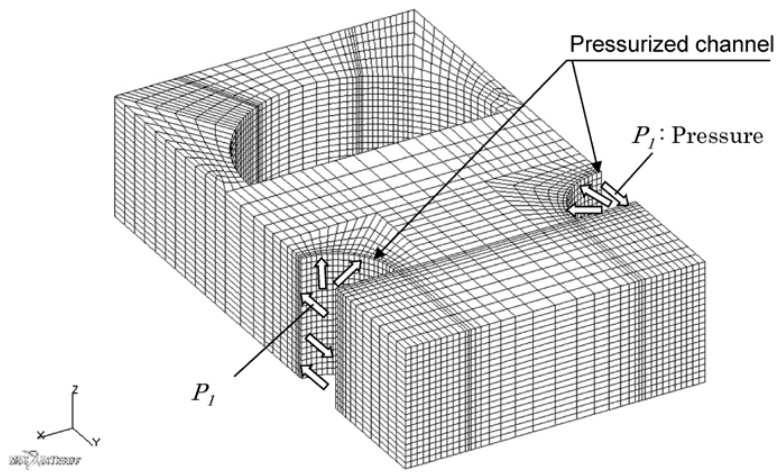

(a)

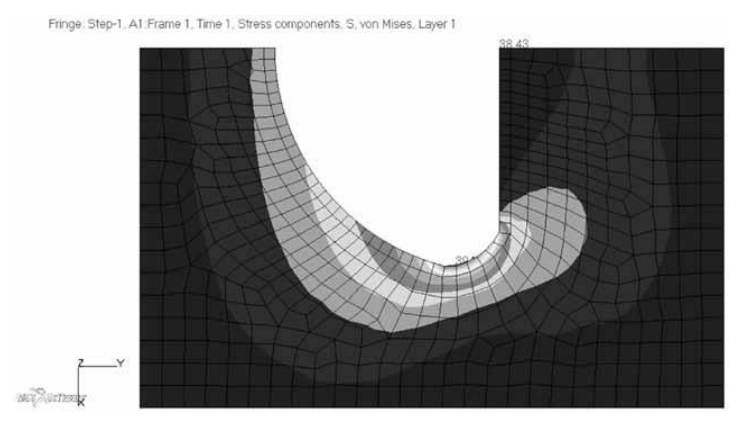

(b)

Fig. 30. (a) Finite element model of etched channels in a hydrogen cooler with pressure on one side only. (b) Pressure stresses in channel. Peaking in " $D$ " corner is observed, but corner radius is expected to be much smaller (higher peak stresses) in actual microchannel designs. After Ref 5. Reprinted with permission.

\section{Service Level A - D Limits}

The load controlled stress limits outlined in Division 5, Fig. HBB-3221-1 apply to Service Levels A through $\mathrm{D}$ and are based on primary stresses resulting from pressure and mechanical loads. The stress intensity allowables are temperature and time dependent out to lifetimes of 300,000 hours, exceeding the 100,000-hour lifetime associated with the stress allowables that were used earlier to size the channels. However, the allowable for the various Service Levels are compared to stress intensities developed from operating stresses at operating temperatures, rather than design conditions. The application of these rules to the heat exchanger macro-scale (sidewalls, headers, etc.) is straightforward.

At the channel scale, primary membrane and bending stresses can be obtained from simple hand calculations as described earlier or from finite element analyses for a pressurized array of channels like that shown in Fig. 30. The design rules for allowable stresses at the channel scale are also provided in Division 5, Table HBB-3221-1 for load controlled conditions. It is interesting to note that the entire core 
expands due to internal pressure which affects stresses at the macro scale as well. The overall expansion of the core due to internal pressure will impact heat exchanger sidewall, endwall, stack endplate and header weld stresses and must be considered. (But see the discussion on potential orthotropic complications below.)

An interesting situation appears when the channels on the two sides are of similar size and areal density and subject to similar pressures, as in a gas-to-gas heat exchanger. In this case, the stress components become nearly equal (hydrostatic) and the von Mises stress and stress intensity vanish (see Reference 16). The stress state changes if one considers the case where the pressure on one side declines to zero under upset conditions, as required by the Code. Then the channel wall stresses in the pressurized channels approach levels similar to those used for channel sizing, where each channel layer is assumed to be selfsupporting. It is probably overly conservative to assume the zero pressure upset occurs under Service Level A or B conditions, but it should be considered for Service Level D and maybe for Service Level C, probably as dictated by the Design Specification.

\section{Strain and Deformation Limits}

In addition to primary stresses, the determination of thermal stresses is the key for the calculation of creep strains, thermal deformations and peak stresses for fatigue usage estimates. From a Code standpoint, calculation of thermal stresses/strains in the heat exchanger is relatively straightforward, but very involved, as we show in following sections.

\section{Thermal Stresses}

While we conservatively size the channel wall, heat exchanger wall and header dimensions using design conditions, the stress allowables used are based on a 100,000 hour creep rupture allowable. Therefore, sufficient margins between design and operating temperatures and pressures must be established at the design stage to accommodate longer design lives considering the potentially large steady state thermal stresses that will affect the creep life of the component. Thermal stresses imposed globally on the core channel array are produced by the large temperature differences the IHX is exposed to and by the constraint provided by the side/end walls and headers. Consequently, before the channel design can be completed, thermal stresses must be evaluated in a Section III design.

\section{Channel Scale Thermal Stresses}

On the millimeter scale associated with the channel laminae, thermal stresses resulting from heat flow from one row of channels to another are expected to be small. This is because the channel walls are thin and it is difficult to develop large temperature differences across short distances. That is not to say these heat conduction thermal stresses should not be calculated, but rather they are unlikely to be controlling. Calculating such stresses is straightforward using finite element methods on a model containing an array of channels.

\section{Macroscopic Thermal Stresses}

As noted earlier, the macroscopic thermal stresses on the scale shown in Fig. 29 must be estimated. Several assumptions may be required to progress in this area, as follows:

- $\quad$ Thermal stresses in the HX are driven by the inlet and outlet temperatures of fluids A and B and the structural constraint of the HX walls and headers acting on the core.

- An average metal temperature at any point in the core region can be locally defined based on the two fluid temperatures in nearby channels. 
- The temperature of the perforated side plates (see Fig. 29) is simply the fluid temperatures $\mathrm{T}_{\mathrm{A}}$ or $\mathrm{T}_{\mathrm{B}}$ associated with the appropriate inlet or outlet flow.

- During normal operation and during thermal transients, the core is in local thermal equilibrium with the heat transfer fluids. That is, it is thermally quick, and a local average metal temperature distribution can be defined throughout the transient at each point in the core in a step-wise equilibrium fashion.

- $\quad$ The core and perforated side plate mechanical and thermal properties can be incorporated in a homogeneous effective medium model. The effective medium smooths out the presence of the channels, but channel symmetries are reflected in potentially orthotropic mechanical properties of the effective medium.

The thermal stress "strategy" is to: (1) model the macrocomponents of the HX shown in Fig. 29, (2) use the thermal hydraulic model to define an average temperature at each point in the core and perforated side plates, and (3) let metallic conduction and fluid-structure heat transfer bring the structure to thermal equilibrium. Resulting stresses or strains can be obtained and evaluated on a macroscopic level for steady state (normal operating) conditions. Areas of interest are obviously the sidewalls and headers, especially header-to-sidewall welds.

During transients, a similar approach can be taken at each time step. The instantaneous locally averaged core temperature distribution can be determined from the instantaneous thermo-hydraulic conditions for fluid A and B at that time. This temperature distribution causes the core to thermally interact with the walls and nozzles to generate transient thermal stresses. The HX system is allowed to approach thermal equilibrium during the time step, at the end of which another step in the fluid temperatures is applied and the process repeated.

Interactions between the core and sidewalls and headers during transients will be important. For a cooldown transient, the core will tend to shrink, as shown in Fig. 31, where tensile stresses (actually, strains) are generated in the core during cooldown. The situation during cooldown is more complicated in the area of the headers where both side wall bending stresses and tensile stresses are generated, as shown in Fig. 32. Header weld stresses contain both tensile and shear components under these conditions, and may be significant. Fatigue cracking of the perforated side wall at perforations (channels) is also of concern.

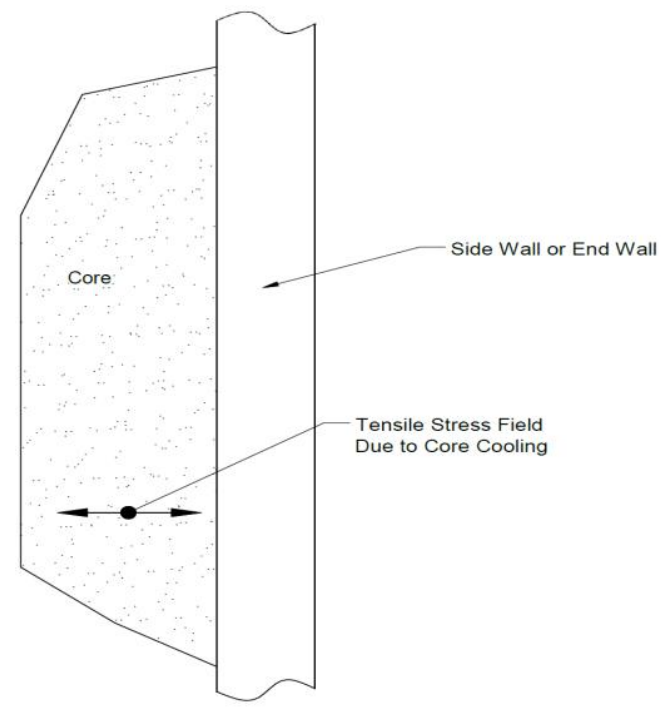

Fig. 31. Thermal stress field near core/sidewall interface. 


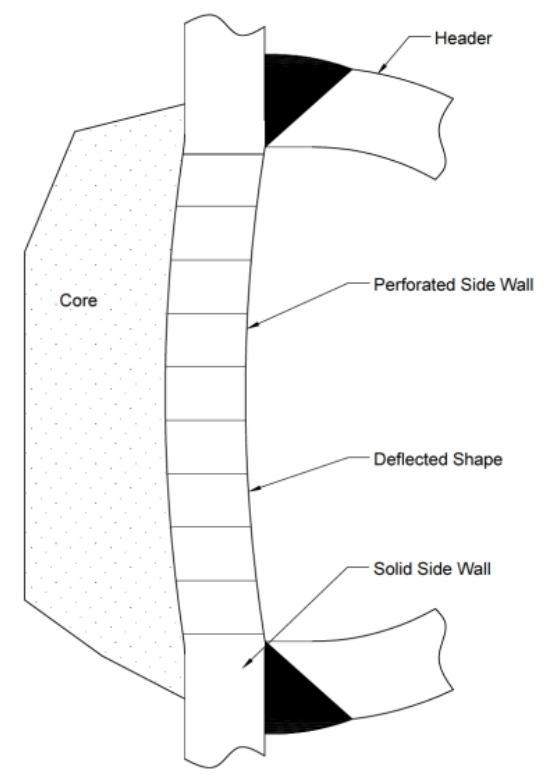

Fig. 32. Complex thermal /mechanical interactions at header locations during core cooling transients.

Finally, it should be noted that the current practice of welding multiple blocks together to form larger heat exchangers (as shown in Figures 20 and 22) will exacerbate thermal stresses, possibly to an unacceptable level. Research work must be performed to determine ways to make larger printed circuit heat exchangers, possibly by providing expansion seals or bellows between blocks and between header sections. Making up a large heat exchanger from separate blocks and headers is also possible, as shown in Fig. 19b. Alternatively, some reduction in stress could be achieved by encapsulating the heat exchanger in a vessel that is filled with the lower pressure fluid. Then the vessel will direct flow to the HX, eliminating one header from each core block.

One such design is shown in Fig. 33, below. 


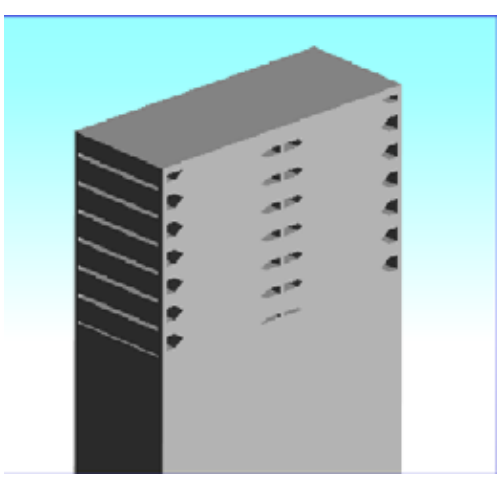

(a)

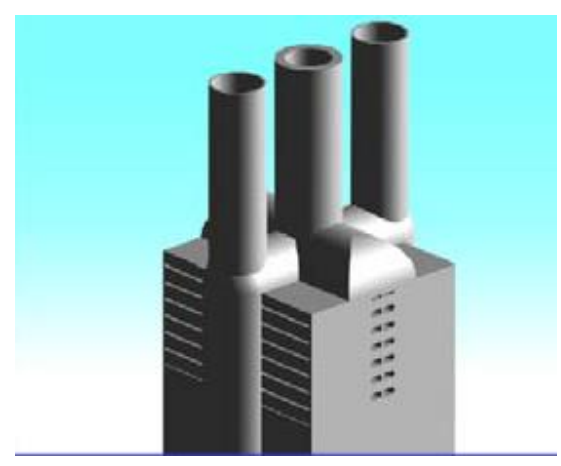

(d)

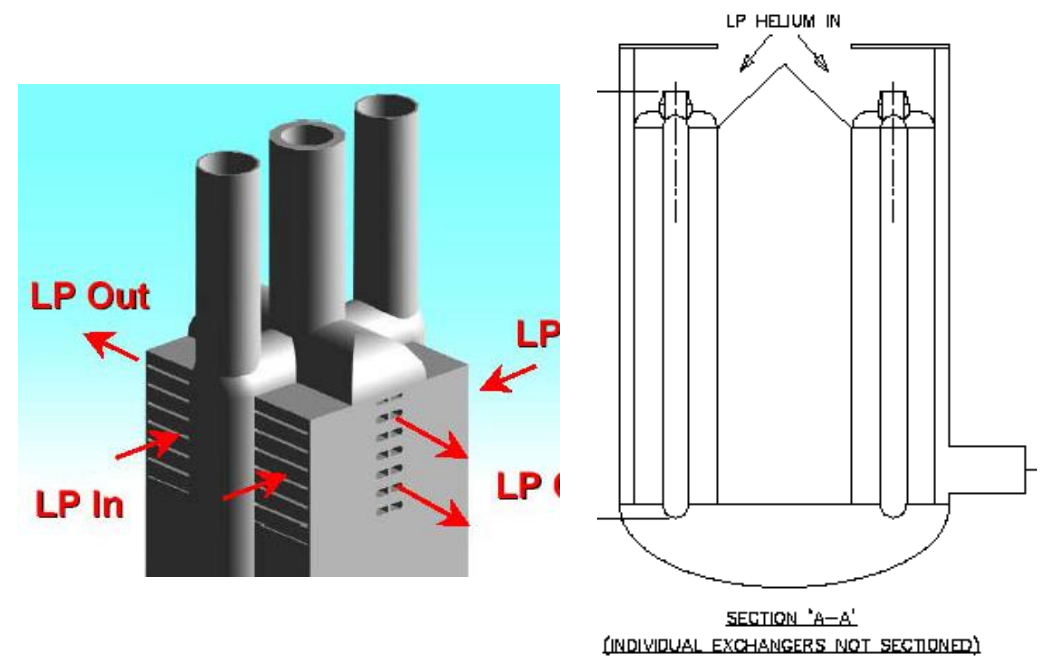

(g)

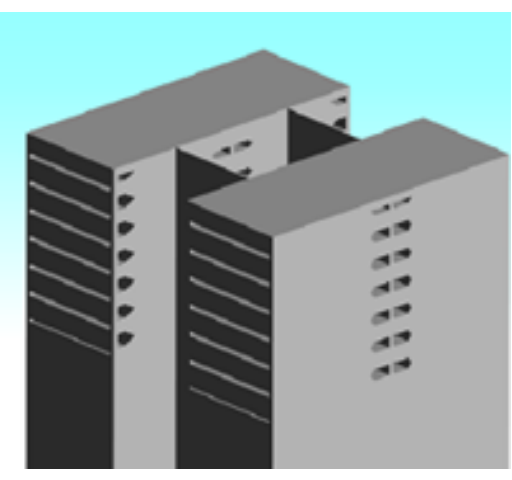

(b)

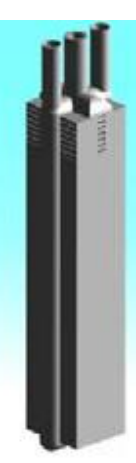

(e)

(h)

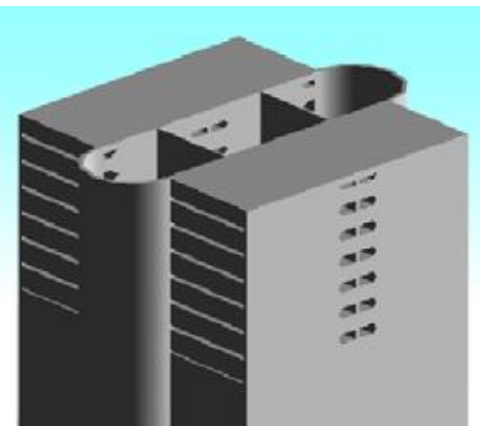

(c)

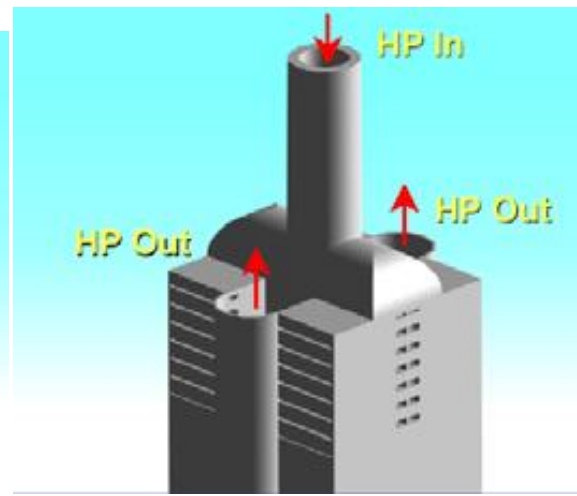

(f)

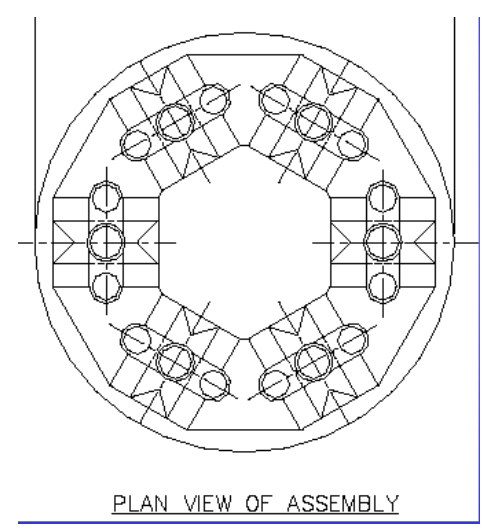

(i)

Fig. 33. (a) through (i) show the design of compact heat exchanger modules inside a Section III vessel. After Ref 13. 


\section{Spatial Temperature Averaging of the Core Temperature}

It is important that the core average temperature distribution be calculated correctly, so that the averaging will provide reasonable thermal strains for the macro-thermal analysis. One could consider simply averaging the fluid temperatures at each point in the core:

$$
T_{a v}=\frac{T_{A}+T_{B}}{2}
$$

but this does not work since we are considering core metal temperature averages, and, in addition, the channel size and thermal hydraulic conditions may be different for fluids A and B. A better approach might be to base the core temperature distribution as a weighted average of the channel $\mathrm{A}$ and $\mathrm{B}$ metal surface temperature, say $\mathrm{T}_{1}$ (for fluid $\mathrm{A}$ ) and $\mathrm{T}_{2}$ (for fluid $\mathrm{B}$ ):

$$
T_{a v}=\frac{T_{1}+w T_{2}}{2}
$$

where we can take the weighting factor, w, as the ratio of the heat transfer areal densities for each channel type:

$$
\begin{aligned}
& \rho_{1}=\frac{\text { total heat transfer surface } A}{\text { unit volume of core }} \\
& \rho_{2}=\frac{\text { total heat transfer surface B }}{\text { unit volume of core }}
\end{aligned}
$$

For the common case shown in Fig. 34 where the laminae are all the same thickness, a simple calculation shows that

$$
\begin{aligned}
\rho_{1} & =\frac{\text { channel A perimeter }}{\text { channel A pitch }}(1 / t) \\
& =\frac{\left(1+\frac{\pi}{2}\right) d_{A}}{p_{A} t} \\
\rho_{2} & =\frac{\text { channel B perimeter }}{\text { channel B pitch }}(1 / t) \\
& =\frac{\left(1+\frac{\pi}{2}\right) d_{B}}{p_{B} t},
\end{aligned}
$$

and where $t$ is the lamina thickness. Finally,

$$
T_{a v}=\frac{T_{1}+\left(\rho_{2} / \rho_{1}\right) T_{2}}{2}=\frac{T_{1}+\frac{d_{B} p_{A}}{d_{A} p_{B}} T_{2}}{2}
$$

where

$$
\left.\begin{array}{l}
T_{1}=T_{A}-\frac{Q_{A}}{h_{A}} \\
T_{2}=T_{B}+\frac{Q_{B}}{h_{B}}
\end{array}\right\} \quad T_{A}>T_{B}
$$

$\mathrm{Q}$ is the local heat flux and $\mathrm{h}$ is the heat transfer coefficient appropriate for the fluid velocity and position along the channel. For the upset case where one side depressurizes, say side B, the heat flux vanishes and $\mathrm{T}_{a v}=\mathrm{T}_{\mathrm{A}}$, where $\mathrm{T}_{\mathrm{A}}$ is spatially, but not necessarily temporally invariant. 


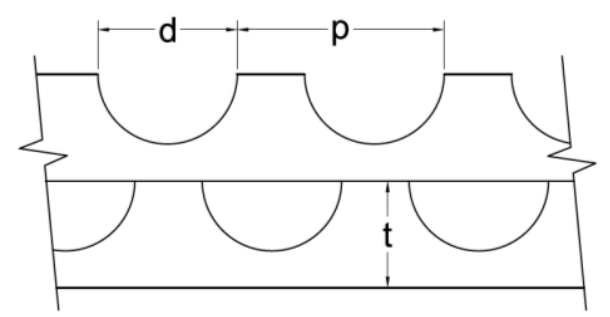

Fig. 34. Model suggested here for calculating areal density of channels.

\section{Effective Medium Approach for Thermal Stresses}

The task of modeling the core and perforated sidewalls explicitly with their thousands of channels would be dramatically simplified if an "effective medium" approach could be used for mechanical and thermal properties. The channel geometry is orthotropic; that is, the stiffness and thermal expansion properties differ in the 1,2, and 3 directions shown in Fig. 35. This is a problem often encountered in the theory of composite materials like corded pneumatic tires, Reference 15. Here the anisotropy is caused by vacant channels rather than reinforcing cords.

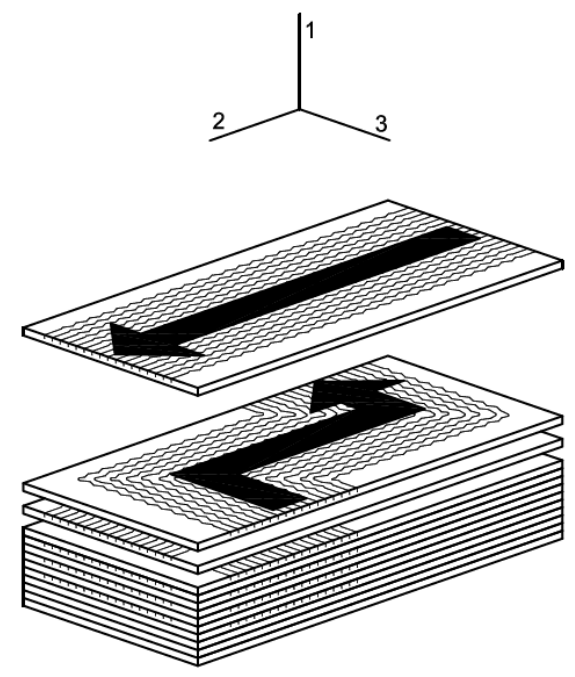

Fig. 35. Principal axes for identifying orthotropic properties.

The approach commonly used to model such structures as a homogeneous, but orthotropic material to account for differing stiffness in the stress-strain relation as follows:

$$
\left[\begin{array}{c}
\varepsilon_{1} \\
\varepsilon_{2} \\
\varepsilon_{3} \\
\gamma_{23} \\
\gamma_{31} \\
\gamma_{12}
\end{array}\right]=\left[\begin{array}{cccccc}
\frac{1}{E_{1}} & \frac{-v_{21}}{E_{2}} & \frac{-v_{31}}{E_{3}} & 0 & 0 & 0 \\
\frac{-v_{12}}{E_{1}} & \frac{1}{E_{2}} & \frac{-v_{32}}{E_{3}} & 0 & 0 & 0 \\
\frac{-v_{13}}{E_{1}} & \frac{-v_{23}}{E_{2}} & \frac{1}{E_{3}} & 0 & 0 & 0 \\
0 & 0 & 0 & \frac{1}{G_{23}} & 0 & 0 \\
0 & 0 & 0 & 0 & \frac{1}{G_{31}} & 0 \\
0 & 0 & 0 & 0 & 0 & \frac{1}{G_{12}}
\end{array}\right]\left[\begin{array}{c}
\sigma_{1} \\
\sigma_{2} \\
\sigma_{3} \\
\tau_{23} \\
\tau_{31} \\
\tau_{12}
\end{array}\right]
$$

The Young's moduli, E, Poisson's ratios, $v$, and shear moduli, $G$, are all allowed to vary in the three symmetry directions. 
For thermal stress analysis, the expansion coefficients can also vary in the three principal directions. Since thermal expansion generates no shear, the principal thermal expansion strains can be simply incorporated into the strain vector. In this case we have (with $\alpha_{1}=\alpha_{2}=\alpha_{3}=\alpha$ )

$$
\left[\begin{array}{c}
\varepsilon_{1}-\alpha_{1} \Delta T \\
\varepsilon_{2}-\alpha_{2} \Delta T \\
\varepsilon_{3}-\alpha_{3} \Delta T \\
\gamma_{23} \\
\gamma_{31} \\
\gamma_{12}
\end{array}\right]=\left[\begin{array}{cccccc}
\frac{1}{E_{1}} & \frac{-v_{21}}{E_{2}} & \frac{-v_{31}}{E_{3}} & 0 & 0 & 0 \\
\frac{-v_{12}}{E_{1}} & \frac{1}{E_{2}} & \frac{-v_{32}}{E_{3}} & 0 & 0 & 0 \\
\frac{-v_{13}}{E_{1}} & \frac{-v_{23}}{E_{2}} & \frac{1}{E_{3}} & 0 & 0 & 0 \\
0 & 0 & 0 & \frac{1}{G_{23}} & 0 & 0 \\
0 & 0 & 0 & 0 & \frac{1}{G_{31}} & 0 \\
0 & 0 & 0 & 0 & 0 & \frac{1}{G_{12}}
\end{array}\right]\left[\begin{array}{c}
\sigma_{1} \\
\sigma_{2} \\
\sigma_{3} \\
\tau_{23} \\
\tau_{31} \\
\tau_{12}
\end{array}\right]
$$

Manipulating the compliance matrices and their inverses (stiffness matrices) and incorporating these orthotropic properties into a finite element method is discussed in the composite materials literature like Reference 15.

It is anticipated that some of the anisotropic properties will be determined by physically applying forces and shears to sections of actual cores. From an economic standpoint, finite element modeling of detailed core sections rather than testing will be required for developing the anisotropic moduli and Poisson's ratios. Code tables or curves providing the anisotropic properties for various channel flow geometries (counterflow, crossflow, etc.), channel pitch and diameter or lamina plate thicknesses will ultimately be required for a simplified Code analysis.

While the macroscopic thermal stresses developed above can be directly applied to solid structures like the solid portions of the sidewalls and the headers and header welds, stresses reported for the core and perforated side plate effective media will not be directly suitable for Code analysis. This is because they are based on a homogeneous model and do not reflect the channel-scale strain concentrations that will develop if an array of channels is mathematically embedded in the macro stress or strain field. Consequently, a model of the core that includes an array of channels $(3 \times 3,5 \times 5$, or larger array) must be embedded in the macroscopic strain field developed in the larger model, and the resulting strain or stress concentrations should be evaluated for peak stresses, fatigue and creep strain limits at the channel-scale level. An array of channels showing peak stress effects is discussed in Reference 16 and shown in Fig. 36 for pressure loading. Note that for cross flow conditions, the model will probably have to be three dimensional and sections taken in the two flow directions. $R \& D$ work should be performed to develop general rules for stress concentration factors for the channels to simplify the Code analysis.

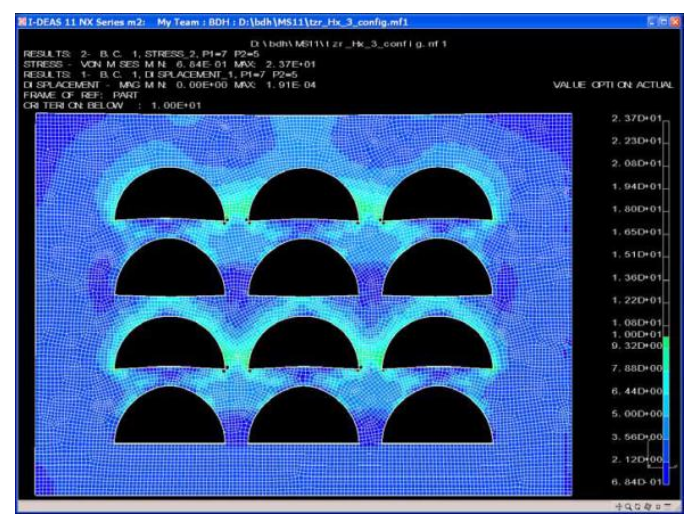

Fig. 36. Channel array finite element model for calculating localized stresses in channel walls. After Ref 16. 


\subsubsection{Elastic-Perfectly Plastic Analysis Methodologies}

As has been noted before, the complex passageways in a compact heat exchanger are a complicating factor for performing the stress analysis required to assess elevated temperature cyclic life under combined pressure and thermal gradient induced stresses. Other complicating factors are the sheer number of structural features to be represented and stress concentrations at the corners of the flow channels. Because of this complexity, it is difficult to apply the normal stress classification process of the ASME Code. However, there are recently developed methodologies based on analysis approaches using an elastic-perfectly plastic (EPP) model to limit various stress measures and strain accumulation.

The EPP methodologies provide conservative bounds to the evaluations of strain limits and creep-fatigue damage under very high temperature conditions which cannot be adequately addressed by the current Division 5 Code rules which are based on the distinction between rate independent plasticity and creep. Such a distinction is invalid in materials operating at very high temperatures. The EPP methodologies also have the advantage of not requiring the process of stress classification in the current Section III Division 5 rules and they are also geared towards the modern finite element analysis tools.

Two ASME Section III, Division 5 Code Cases on strain limits and creep-fatigue evaluations using the EPP methodologies have been developed and the ASME Code committee approval process is on-going.

\subsubsection{Class B Design Rules}

A review of the design requirements in ASME BPV, Section III, Division 5 requires that elevated temperature Class B vessels designed by equation must satisfy the requirements of Division 1, NC-3300, with some exceptions. This approach does not address thermal stresses or cyclic fatigue. The allowable stresses are those listed in Division 5, Mandatory Appendix HCB-II, which are extensions of Tables 1A, $1 \mathrm{~B}$ and 3 of Section II, Part D.

An examination of the design rules in NC-3300 shows that they are very similar to the rules in Section III, Division 1. Thus there appear to be minimal differences between a Section III, Division 5, Class B design and a Section VIII, Division 1 design. Allowable stresses are also similar between Section VIII and Section III, Division 5, Class B where the temperatures overlap. In principle, few changes would be required to Code Case 2621-1 covering diffusion bonded microchannel heat exchangers to make it applicable to Section III, Division 5 Class B rules. Finally, if cyclic stresses are of concern for the design, the use of Class B design rules is probably inappropriate. In that case, a Class A analysis and possibly physical fatigue testing will be required to ensure an adequate design.

\subsubsection{Code Boundaries}

The assumption behind the Section III design methodology outlined above is that the diffusion bonded sidewalls and endwalls are sufficiently robust to act as Class A pressure boundaries. In addition, since a leak between Class A fluid channels and channels in Class B fluid service is a leak in a Class A pressure boundary, core internal diffusion bonds must also be Class A quality. Thus, a heat exchanger containing Class A system fluid is a Class A design and must meet Class A rules. It is probably incorrect to assume that if a heat exchanger is placed in a containment vessel, the vessel can become the nuclear Code boundary and design of the heat exchanger inside can be to ASME VIII rules. A Class A boundary still exists inside the heat exchanger core. For the heat exchanger shown in Fig. 22, the only purely Class B Code boundaries appear to be the Class B inlet and outlet headers. 


\section{INSPECTION AND TESTS}

The non-destructive evaluation requirements for the construction of the diffusion bonded compact heat exchangers are provided in Section VIII Code Case 2621-1. Helium leak testing side-to-side and both sides to external is required. In addition, ultrasonic inspection of side/endwalls in the vicinity of header attachment welds is required, along with the welds themselves. Liquid penetrant and visual examination of all external surfaces (after machining) is required - no penetrant indications and unbound areas are allowed. Finally, hydrostatic testing or pneumatic testing is required to Section VIII, Division 1, UG-99 or UG-100, respectively.

Bonding Procedure Specification and Bonding Performance Qualifications in Section IX of the Code require the production of $8 \times 8 \times 8$-inch bonded test blocks from which full-size tensile specimens are extracted and tested. Three tensile tests in the through-bond and three in the lamina plane direction are required. The minimum properties required in the original base metal specification must be met. In addition, a microstructure sample must be removed from the test block and examined. The sample must show complete fusion along the bond lines and be free of cracks in the bond or parent material.

An evaluation must be conducted to determine if these inspections and tests are sufficient for Section III fabrication. Further, required in-service inspections have to be established. It is likely that more ultrasonic inspection of sidewalls, endwalls and stack ends will be required for fabrication and in-service inspections.

Volumetric inspection of core welds and perforated side plate/end plate welds will probably be impossible. Consequently, weld strength reduction factors applicable to the creep rupture allowable, $S_{\mathrm{r}}$, in Division 5, Subsection HB, Subpart B should also be reviewed. Note that Section VIII, Division 1 welds that are not volumetrically inspected require the use of a 0.7 joint efficiency factor on the allowable stress.

Finally, the need for 100- or 1000-hour creep tests and fatigue tests should be evaluated for bond procedure qualification. We note that Heatric has done some work on creep and fatigue testing of stainless steel printed diffusion bonded blocks, as reported in Reference 8. Kobe Steel has performed fatigue tests on actual stainless steel cores, as reported in Reference 5. Fatigue testing on actual core samples is probably the best approach for determining the fatigue behavior of microchannel designs. 


\section{FOULING}

Little has been published on the fouling performance of microchannel heat exchangers. There is obviously a concern since the channels are so small. The Heatric website discusses the need for in-line filters and for providing header maintenance nozzles to accommodate pressure washing of the core. The fouling potential for the coolants being considered for the high temperature reactor systems (sodium, helium, $\mathrm{sCO}_{2}$ ) are almost completely unknown.

Fouling is a potentially critical issue for the economic feasibility of microchannel heat exchangers. A review of current petrochemical experience with these heat exchangers should be conducted in the near term to better evaluate this potential threat. Experience with cleaning should also be obtained. 


\section{CONCLUSIONS AND RECOMMENDATIONS}

\subsection{CONCLUSIONS}

This report provides a brief review of the literature regarding compact heat exchangers along with a summary of some ASME Code design considerations for the bonded microchannel designs. Based on this review, we conclude the following:

1. The diffusion bond or DFW welding approach appears to produce sound welds with properties similar to the base material.

2. The critical variables for producing diffusion bonds in the high chromium alloys of interest for high temperature service are not public, and thus the sensitivity of the weld quality to these variables is not generally known.

3. The load controlled stresses for the individual channels on the micro scale and the major components of the heat exchanger (core, sidewalls, headers, etc.) on the macro scale are well established based on existing Section VIII, Division 1 designs.

4. Methods for determining thermal stresses in the core and other major components must be developed. One approach is suggested in this paper. There is no generally agreed upon approach for calculating thermal stresses at this time, however.

5. Based on the fast thermal response of the diffusion bonded microchannel core, it is suspected that thermal stresses, especially during transients, will be large.

6. The high thermal stresses combined with the thermal strain concentrations expected in the core near the sidewalls, as well as at header attachment welds, will likely limit the design life to less than 40 years.

7. The fact that most of the core diffusion bonds cannot be volumetrically inspected will be a problem for acceptance of the design for ASME nuclear service. Current NDE requirements for Section VIII heat exchangers will have to be augmented and in-service inspection requirements will have to be developed essentially from scratch.

8. The potential for fouling of the microchannels is great and viable methods for cleaning a contaminated, radioactive core have not been developed.

\subsection{RECOMMENDATIONS}

Based on our conclusions, we suggest the following research topics be considered to support the technical development of the compact heat exchanger for nuclear service:

1. Welding development programs for diffusion bonding or DFW should be continued to establish details of the currently accepted and possibly additional essential welding variables.

2. A Division 5, Class A stress analysis should be performed on a sample heat exchanger design. Analysis methods for load controlled and strain controlled stresses should be developed and applied. As a first cut, an evaluation using assumed isotropic core properties should be performed to obtain early estimates of expected thermal stresses and possible design lifetimes. 
3. The simplified analysis methods in Division 5, Appendix HBB-T employ the Bree approach which considers the simultaneous application of primary and thermal loads for the purpose of evaluating of elastic "shakedown" and ratcheting. This approach should be reviewed to determine if it is applicable when macro thermal stresses caused by global constraint like that produced by the heat exchanger walls and headers are imposed on an array of small channels like those in the PCHE core. On the channel size scale, the imposed thermal stresses may look like primary stresses since they may cause large local channel strains without self relief.

4. The development of an alternate Section III, Division 5 structural design methodology based on the application of the EPP methodologies that provide for the assessment of the elevated temperature failure modes of a compact heat exchanger under sustained and cyclic loading due to pressure and thermal gradients should be pursued.

5. Research should be performed regarding the development of methods for determining the orthotropic properties of a diffusion bonded core. Eventually, such properties should be incorporated into the Code.

6. Rules for inspection and testing during fabrication and for in-service inspections should be developed.

7. The potential for fouling of the microchannels should be explored based on the service experience of current Section VIII vessels and on testing. Methods for cleaning should also be explored and tested. 


\section{REFERENCES}

1. Piyush Sabharwall, Denis E. Clark, Ronald E. Mizia, Michael V. Glazoff and Michael G. McKellar, "Diffusion-Welded Microchannel Heat Exchanger for Industrial Processes, “ Journal of Thermal Service and Engineering Applications, 5, (March 2013), 01109-1.

2. F. Jalilian, M. Jahazi and R. A. L. Drew, "Microstructure Evolution During Transient Liquid Phase Bonding of Alloy 617," Metallogr. Microstruct. Anal., 2 (2013), 170.

3. Hu Chen, Jianming Gong, Luyang Geng, and Shan-Tung Tu, "Finite Element Prediction of Residual Stresses and Thermal Distortion in Brazed Plate-Fin Structure," Journal of Pressure Equipment and Systems, 3 (2005), 118.

4. Stephen John Dewson and Xiuqing Li, "Selection Criteria for the High Temperature Reactor Intermediate Heat Exchanger," Proceedings of ICAPP '05, Paper 5333, May 15-19, 2005.

5. Yusutake Miwa, Dr. Koji Noishiki, Tomohiro Suzuki and Kenichi Takasuki, "Manufacturing Technology of Diffusion-Bonded Compact Heat Exchanger (DHCE)," Kobelco Technology Review, 32 (2013), 51.

6. Renaud Le Pierres, David Southall and Stephen Osborne, "Impact of Mechanical Design Issues on Printed Circuit Heat Exchangers," Proceedings of $\mathrm{SCO}_{2}$ Power Cycle Symposium 2011, May 2425, 2011.

7. David Southall and Stephen John Dewson, "Innovative Compact Heat Exchangers," Proceedings of ICAPP '10, June 13-17, 2010, Paper 10300, American Nuclear Society.

8. David Southall, "Diffusion Bonding in Compact Heat Exchangers," Proceedings of ICAPP '09, May 10-14, 2009, Paper 9069, American Nuclear Society.

9. David Southall, Renaud Le Pierres and Stephen John Dewson, "Design Considerations for Compact Heat Exchangers," Proceedings of ICAPP '08, June 8-12, 2008, Paper 8009, American Nuclear Society.

10. Xiuqing Li, Renaud le Pierres and Stephen John Dewson, "Heat Exchangers for the Next Generation of Nuclear Reactors," Proceedings of ICAP '06, June 4-8, 2006, Paper 6105.

11. Sai K. Mylavarapu, Xiaodong Sun, Richard N. Christensen, Raymond R. Unocic, Richard E. Glosup, and Mike V. Patterson, "Fabrication and Design Aspects of High-Temperature Compact Diffusion Bonded Heat Exchangers," Nuclear Engineering and Design, 249 (2013), 49.

12. Xiuqing Li, David Kininmont, Renaud Le Pierres and Stephen John Dewson, "Alloy 617 for the High Temperature Diffusion-Bonded Compact Heat Exchangers," Proceedings of ICAPP '08, June 8-12, 2008, Paper 8008.

13. V. Dostal, M. J. Driscoll and P. Hejzlar, "A Supercritical Carbon Dioxide Cycle for Next Generation Nuclear Reactors,” MIT-ANP-TR-100, March 10, 2004.

14. Piyush Sabharwall, Eung Soo Kim, Ali Siahpush and Mike Patterson, "Preliminary Design for Conventional and Compact Secondary Heat Exchanger in a Molten Salt Reactor," INL/CON-1226385, July, 2012. 
15. The Pneumatic Tire, DOT HS 810561, National Highway Traffic Safety Administration, February, 2006, Chapter 4.

16. T. M. Lillo, R. L. Williamson, T. R. Reed, C. B. Davis and D. M. Ginosar, "Engineering Analysis of Intermediate Loop and Process Heat Exchanger Requirements to Include Configuration Analysis and Materials Needs," INL-EXT-05-00690, September, 2005.

17. J. Kesseli, J. Nash, A. Corbeil, Brayton Energy, LLC Presentation, "Plate Fin Heat Exchanger Design for the Supercritical $\mathrm{CO}_{2}$ Cycle," Symposium on Supercritical $\mathrm{CO}_{2}$ Power Cycle for Next Generation Systems, March 6, 2007.

18. Scott R. Penfield, Jr., Phillip L. Rittenhouse, Renee Greyvenstein, James Nash, "IHX Design and Development for the Next Generation Nuclear Plant," Proceedings of the $4^{\text {th }}$ International Topical Meeting on High Temperature Reactor Technology, September 28-October 1, 2008 
Distribution List

\begin{tabular}{|l|l|l|}
\hline Name & Affiliation & Email \\
\hline Carlson, M. & SNL & mcarlso@ sandia.gov \\
\hline Corwin, W. & DOE & william.corwin @ nuclear.energy.gov \\
\hline Croson, D. & INL & Diane.Croson@ @inl.gov \\
\hline Fleming, D. & SNL & ddflemi@ sandia.gov \\
\hline Gougar, H. & INL & hans.gougar@inl.gov \\
\hline Grandy, C. & ANL & cgrandy@anl.gov \\
\hline Hill, R.N. & ANL & bobhill@anl.gov \\
\hline Jetter, R.I. & Consultant & bjetter@ sbcglobal.net \\
\hline Majumdar, S. & ANL & majumdar@ anl.gov \\
\hline Nestell, J. & MPR & jnestell@mpr.com \\
\hline Petti, D. & INL & David.Petti@inl.gov \\
\hline Reeves, S. & DOE & Steven.Reeves @ Nuclear.Energy.gov \\
\hline Robinson, B. & DOE & brian.robinson@ nuclear.energy.gov \\
\hline Rochau, G. & SNL & gerocha @ sandia.gov \\
\hline Sham, T.-L. & ORNL & shamt@ornl.gov \\
\hline Sienicki, J. & ANL & sienicki@anl.gov \\
\hline Sink Jr, C.J. & DOE & carl.sink@ nuclear.energy.gov \\
\hline Wang, J.-A. & ORNL & wangja@ornl.gov \\
\hline Wright, R.N. & INL & richard.wright@inl.gov \\
\hline
\end{tabular}

